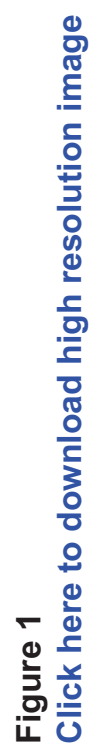
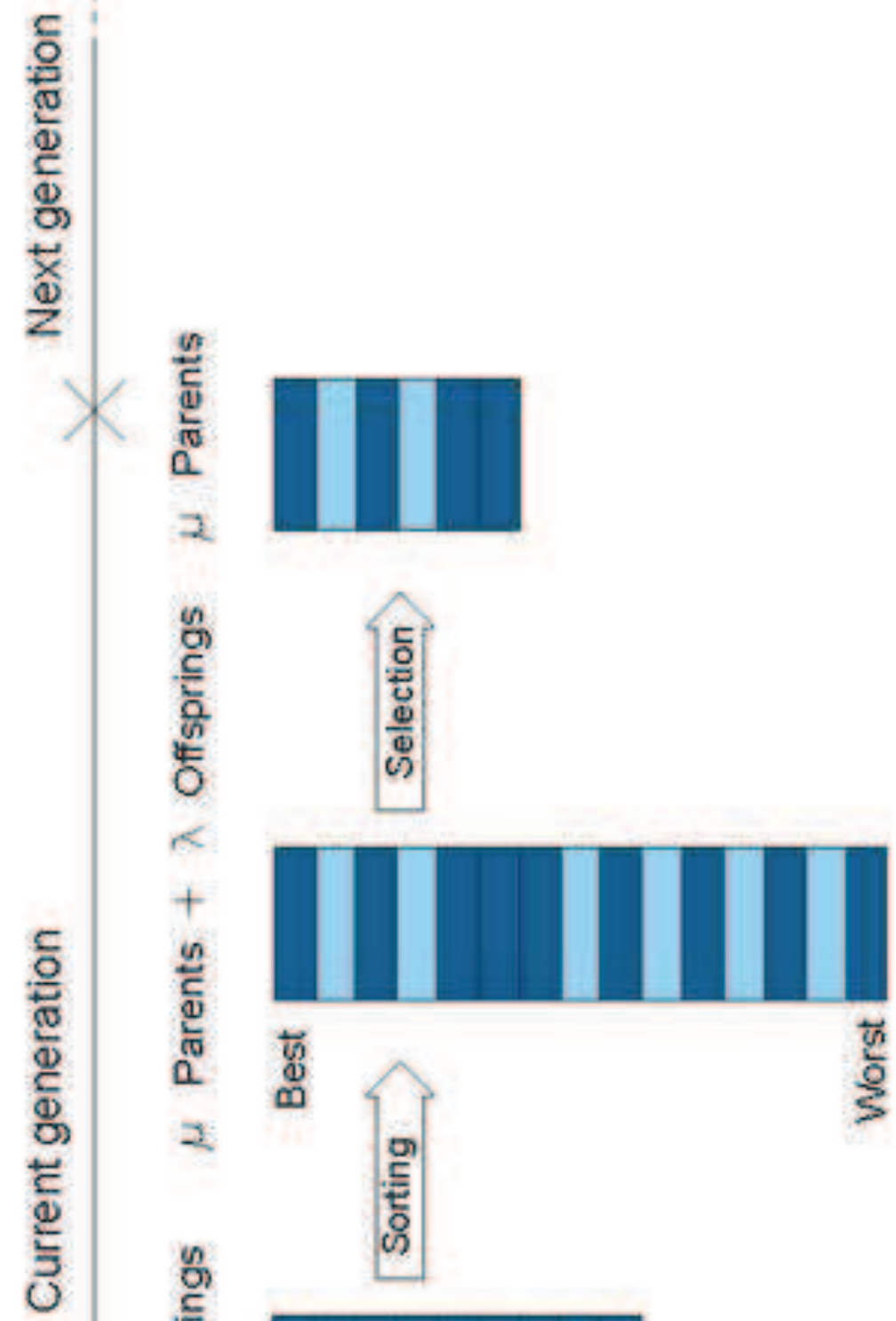

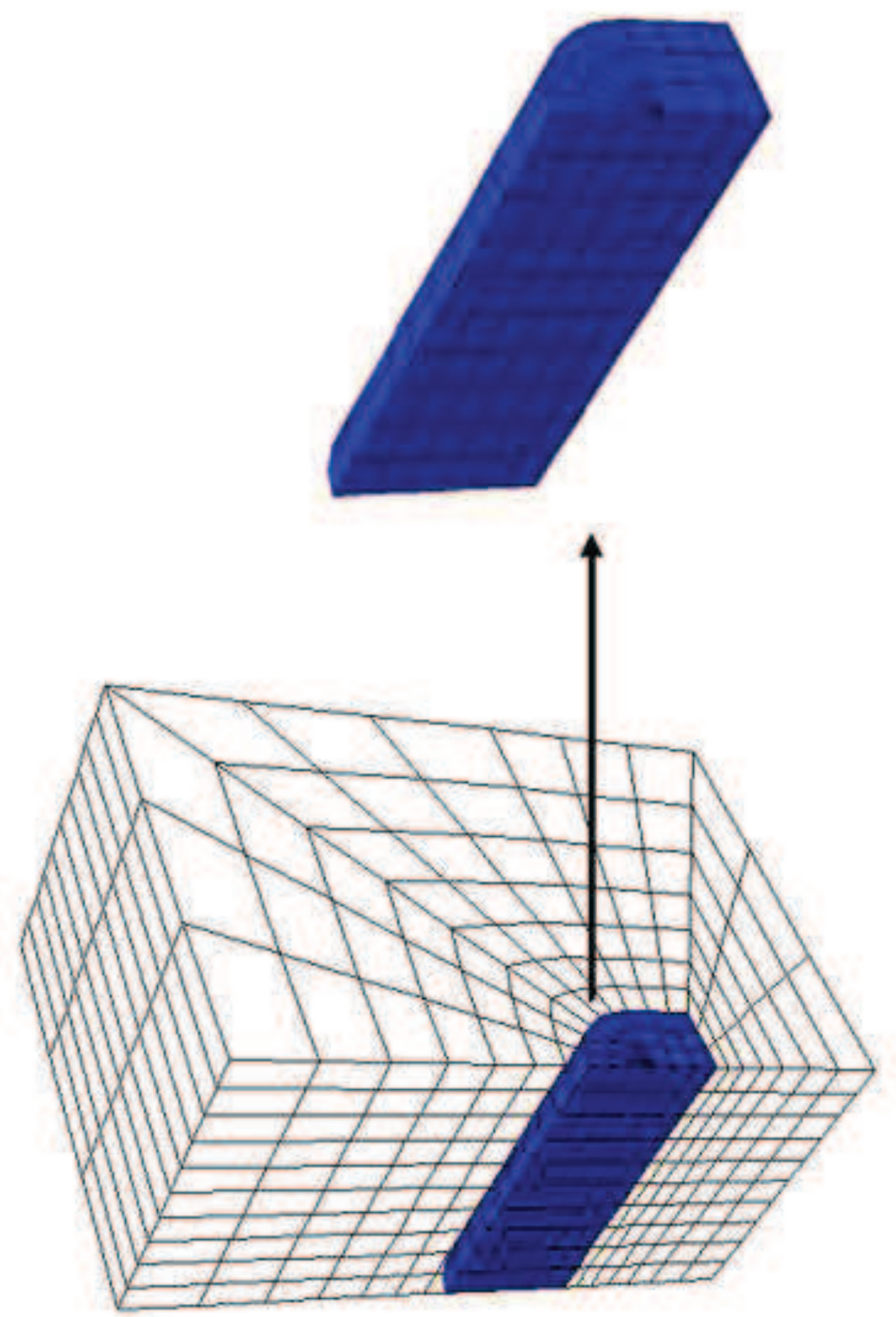

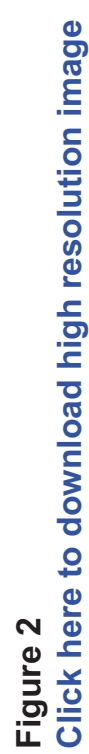


Displacements:

Surface

Arch

Wall

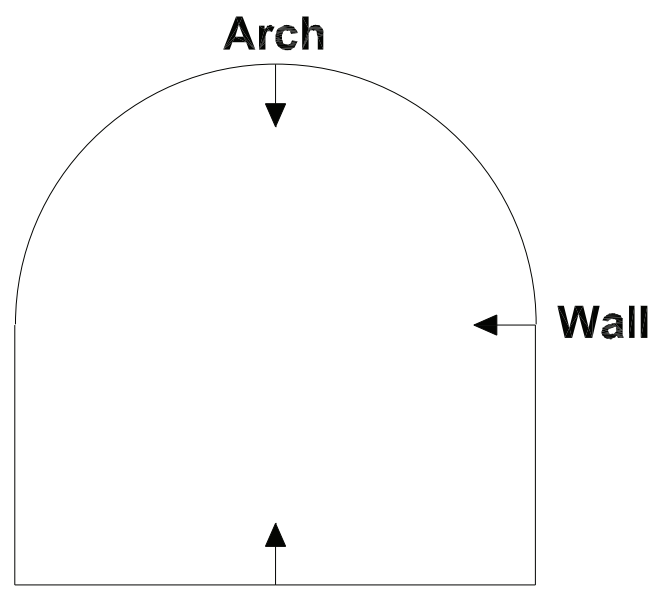

Floor

Stresses:

Wall 


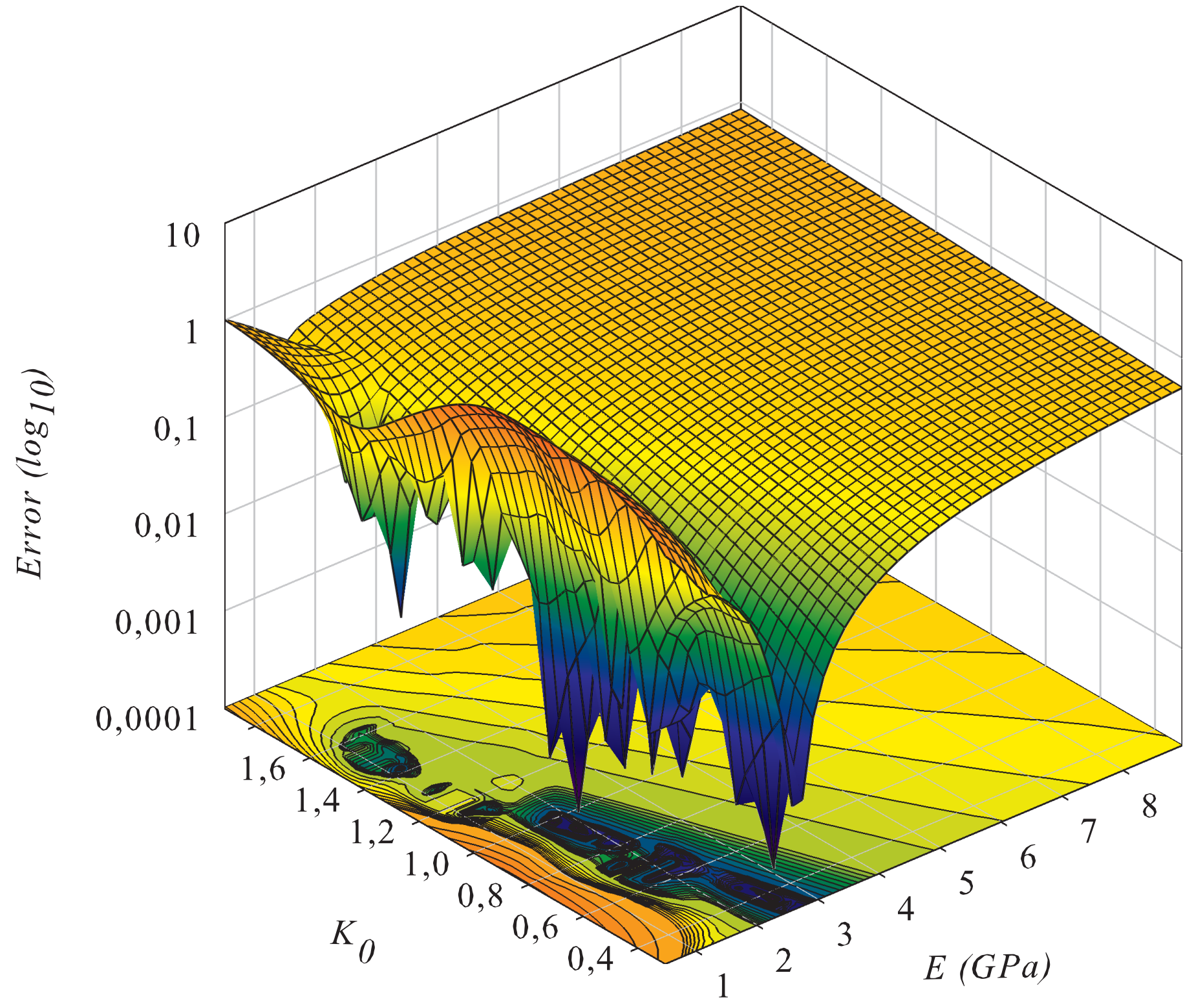

(a) 


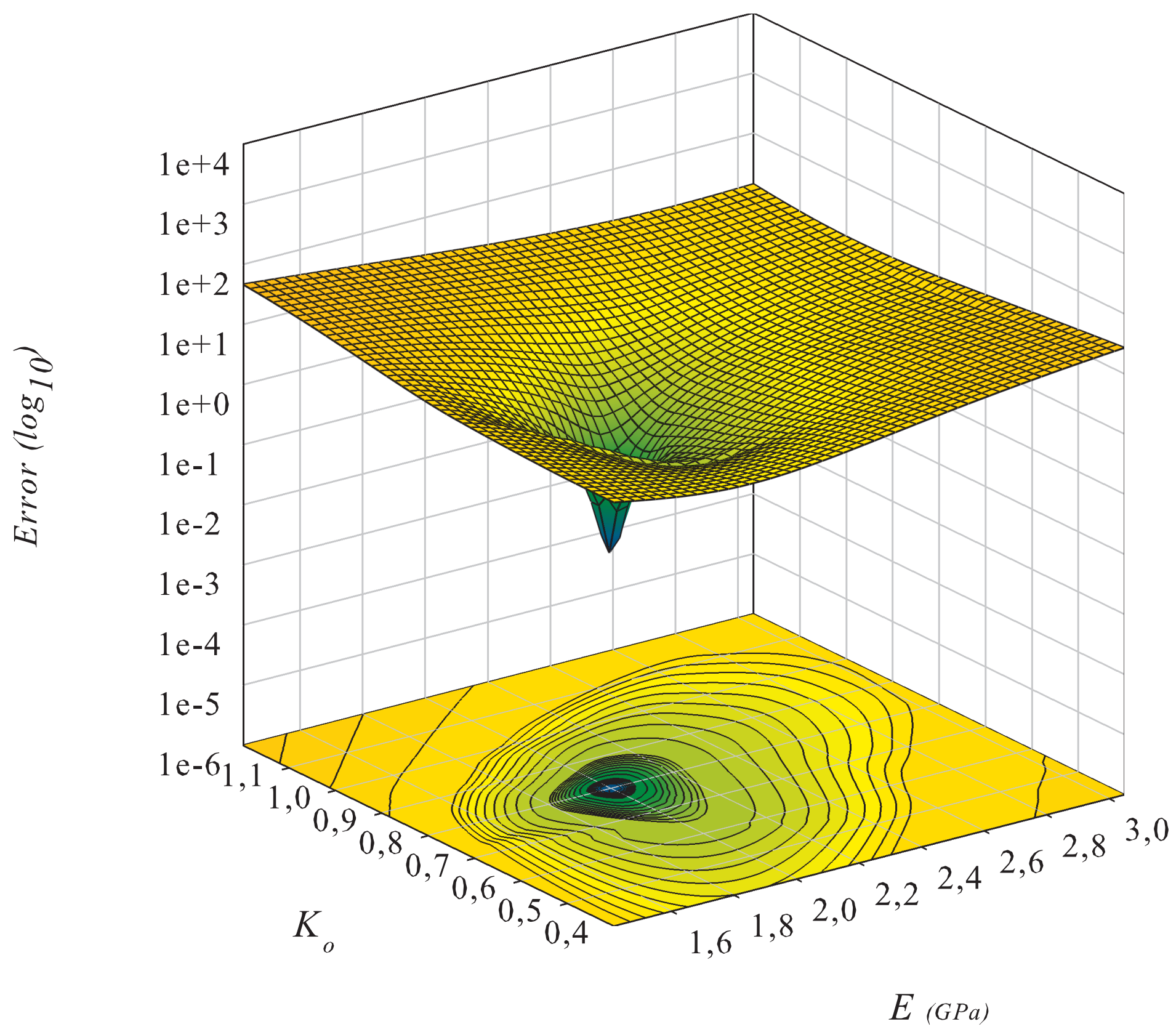

a) 


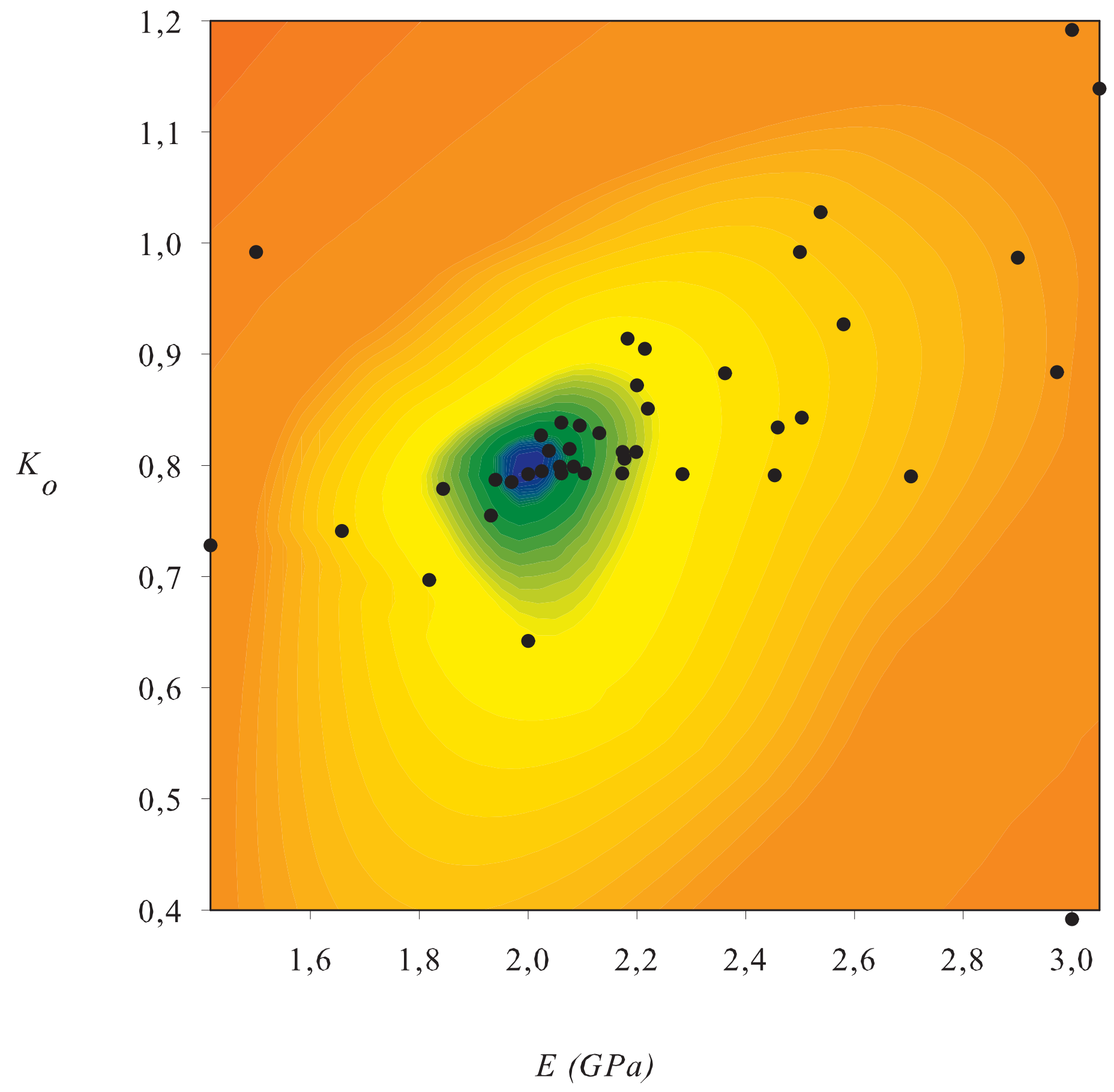

(b) 


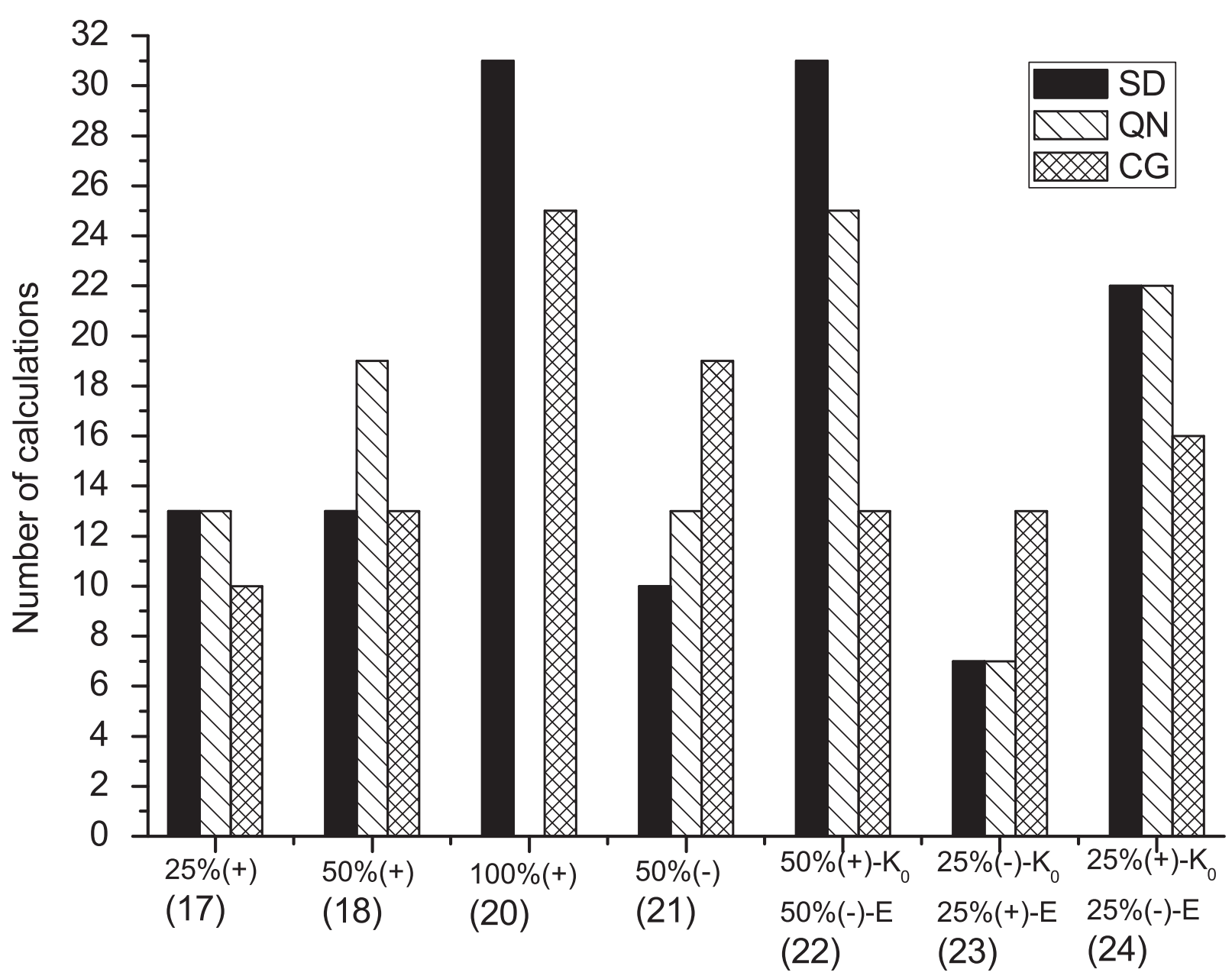




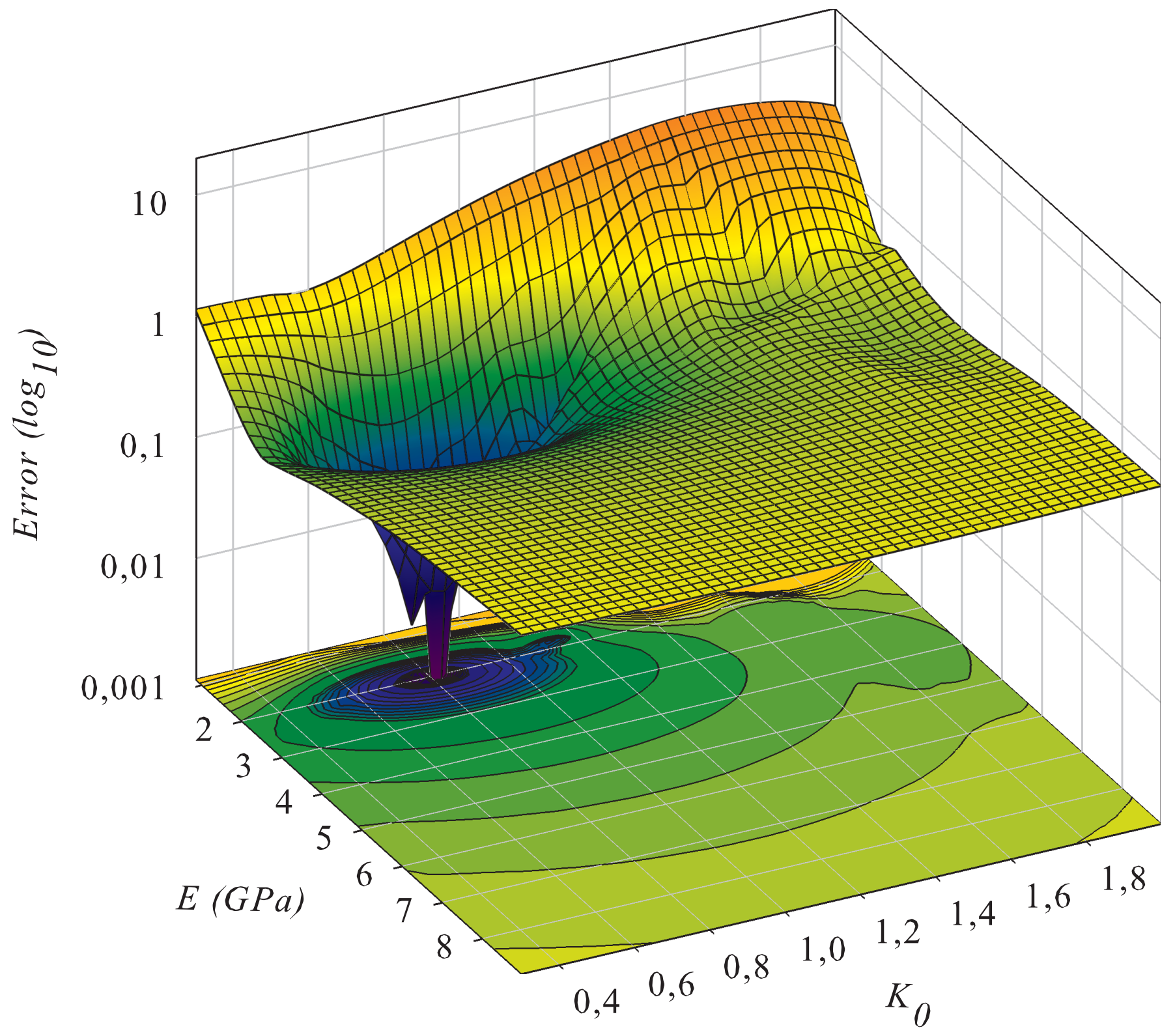

(a) 


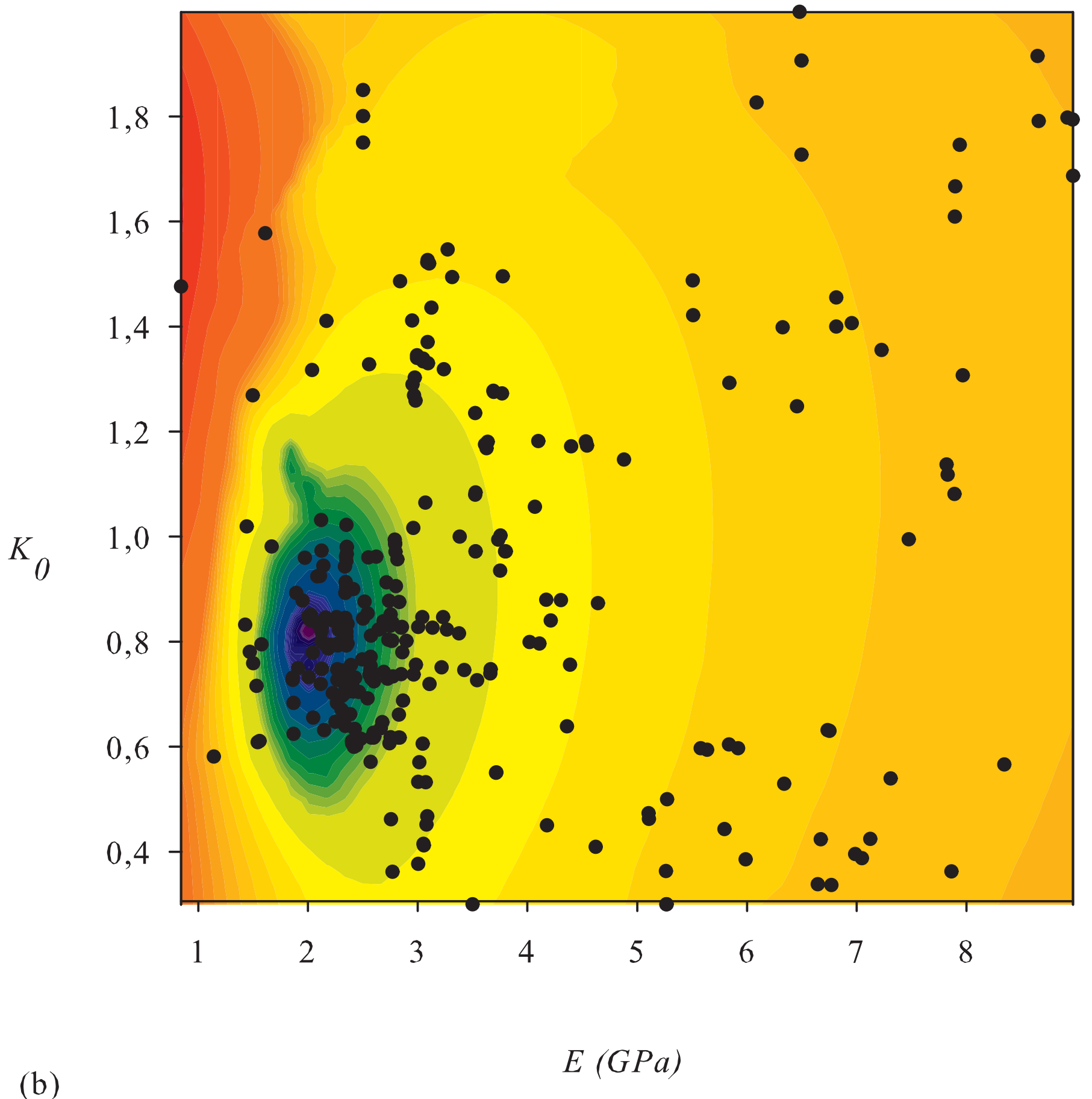




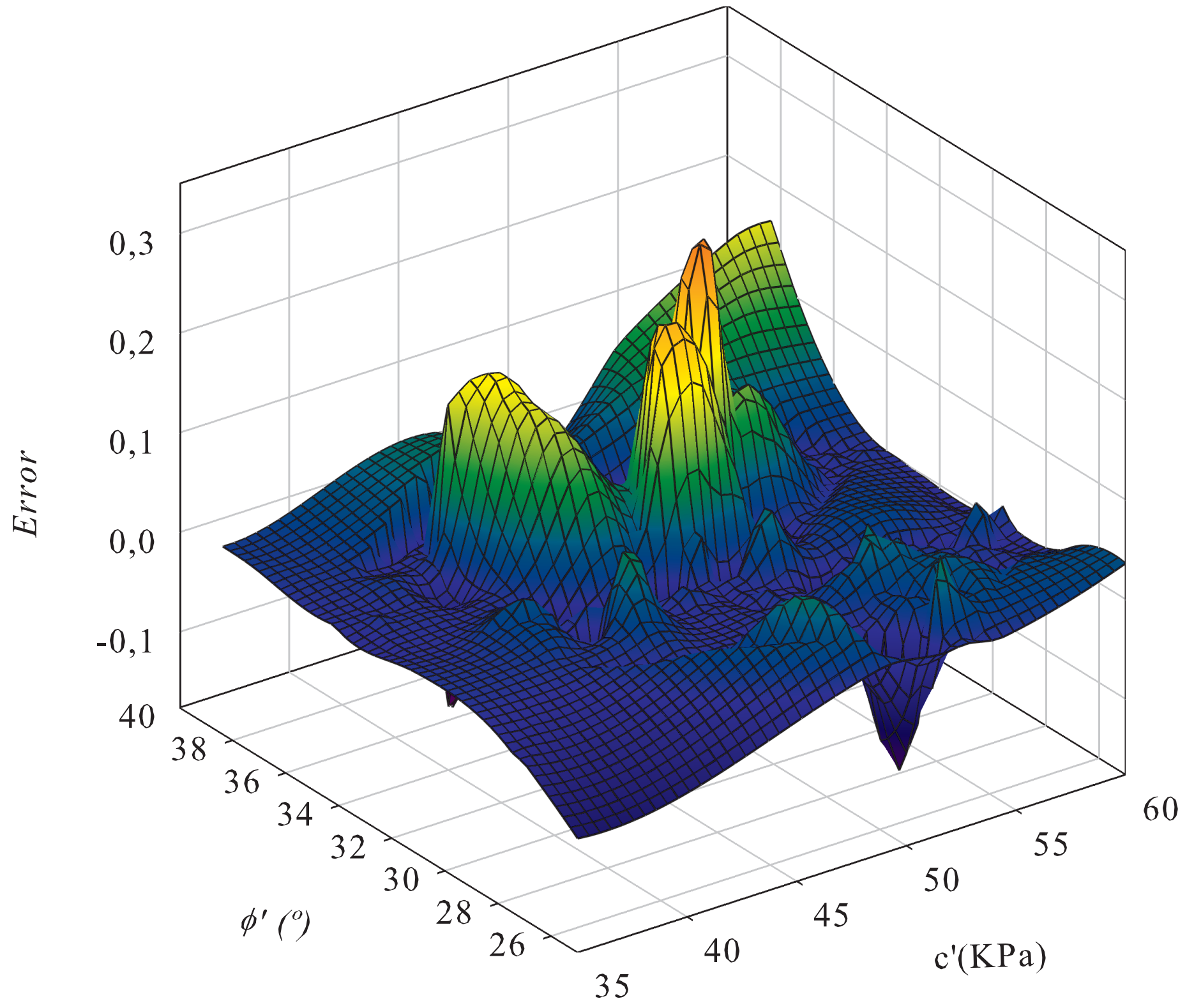

(a) 


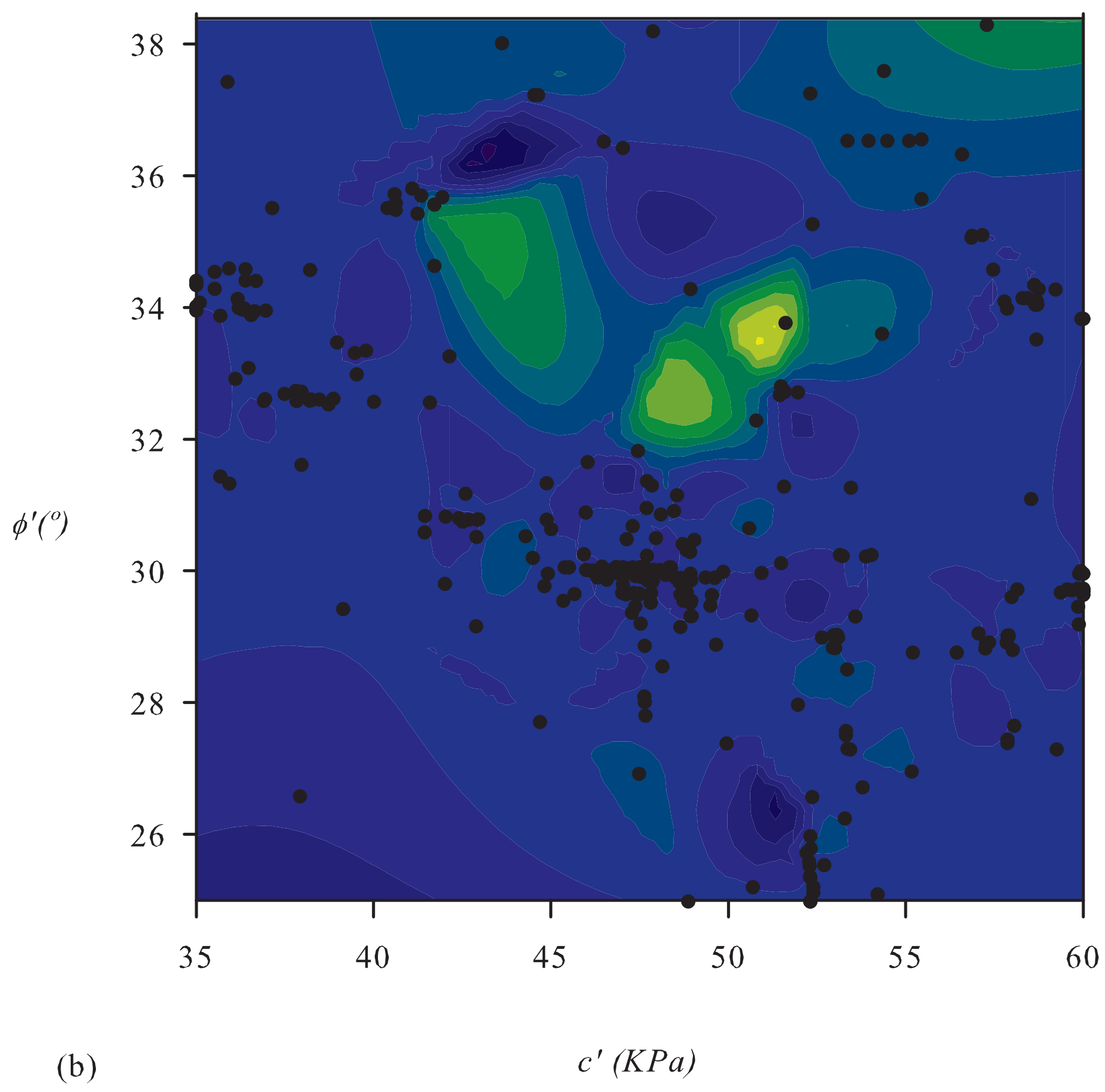




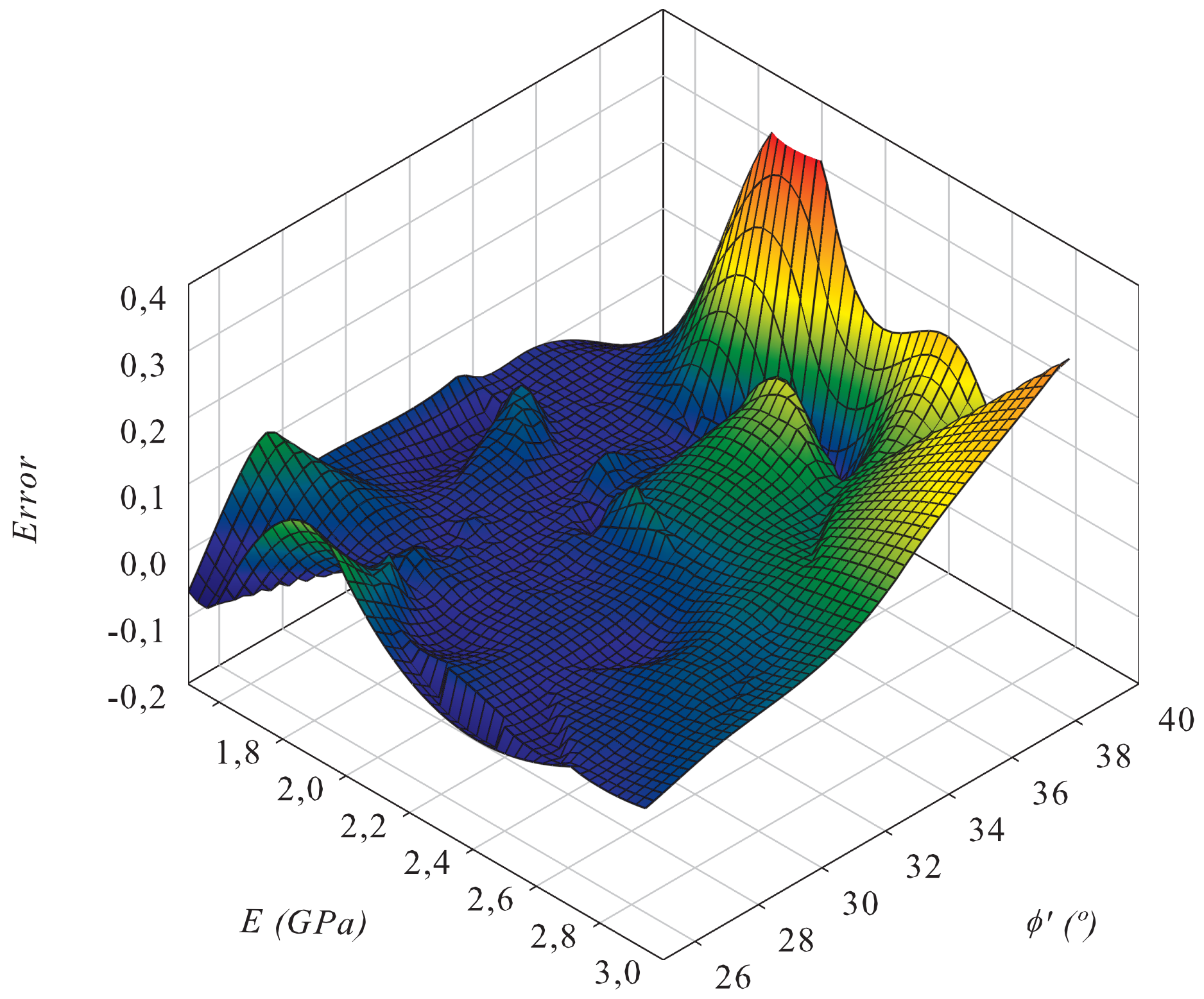

(c) 


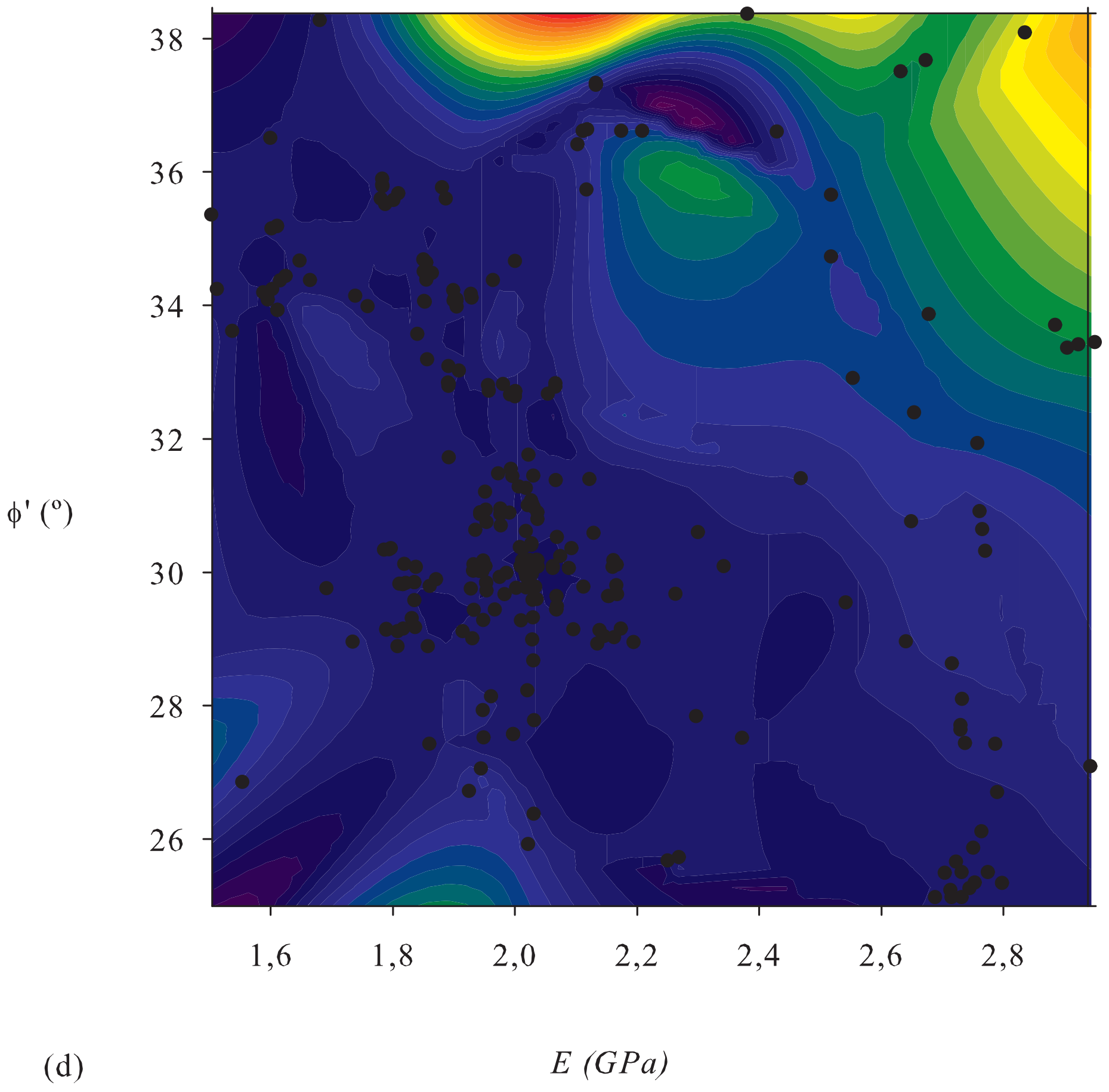




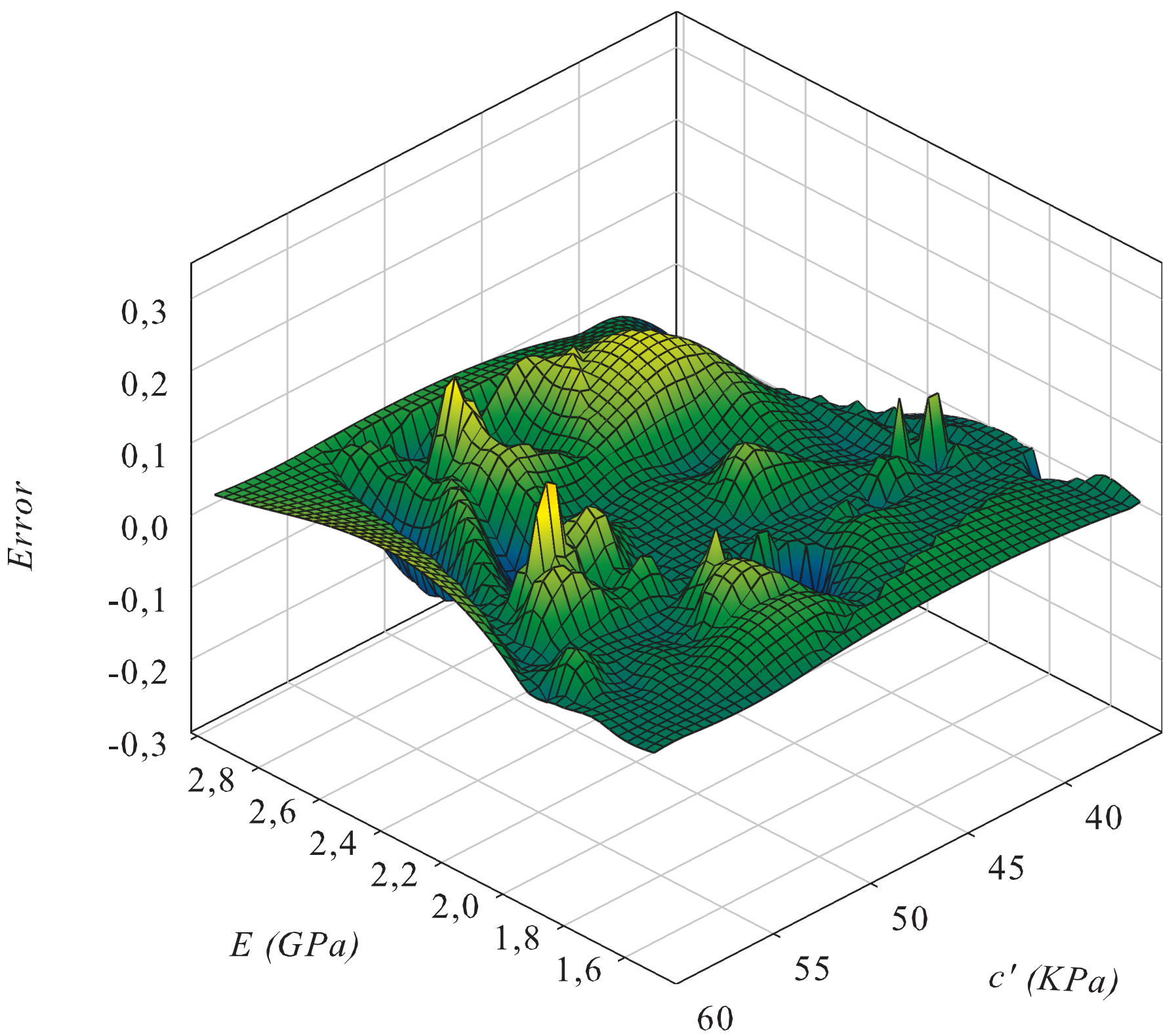

(e) 


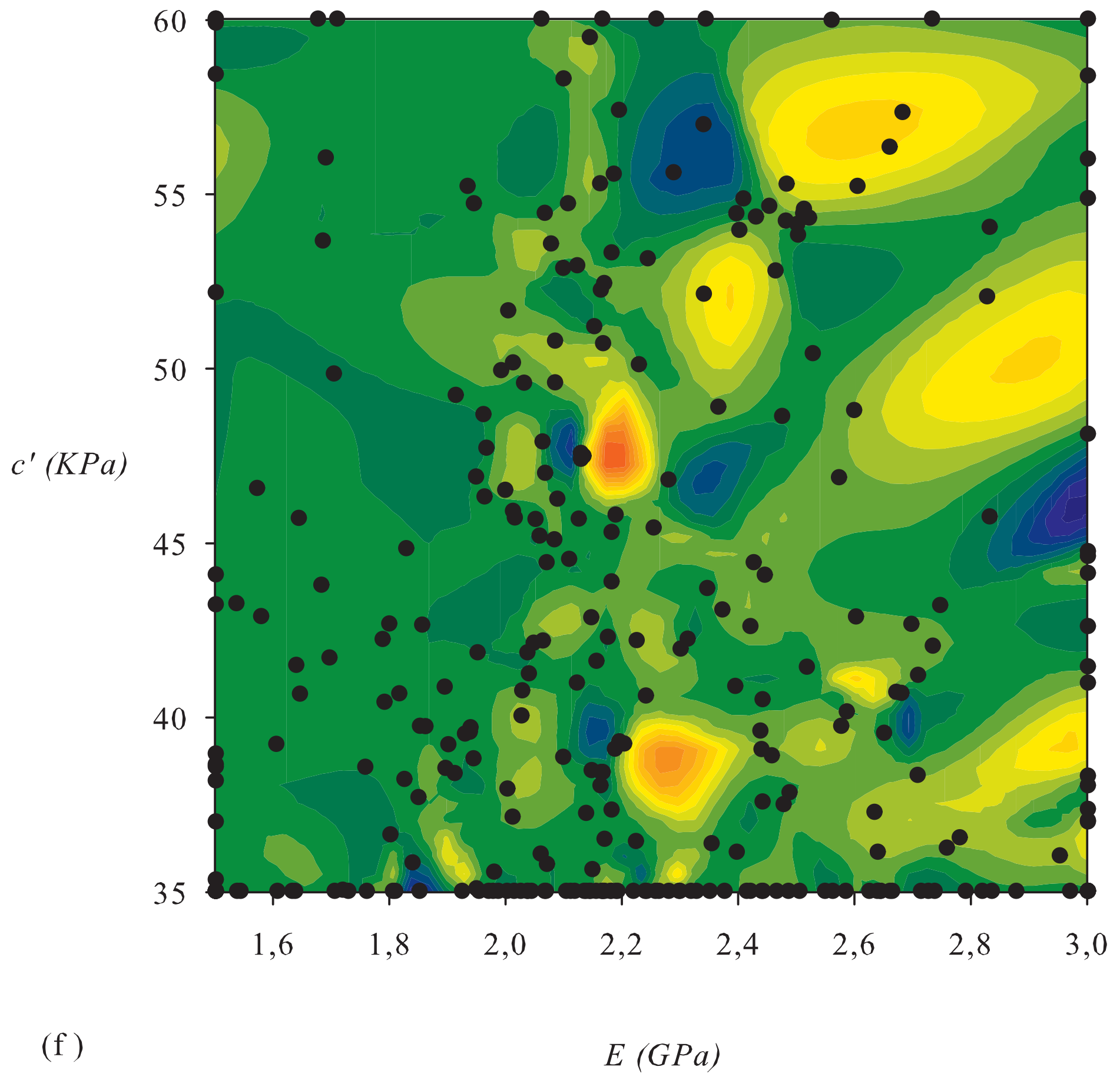




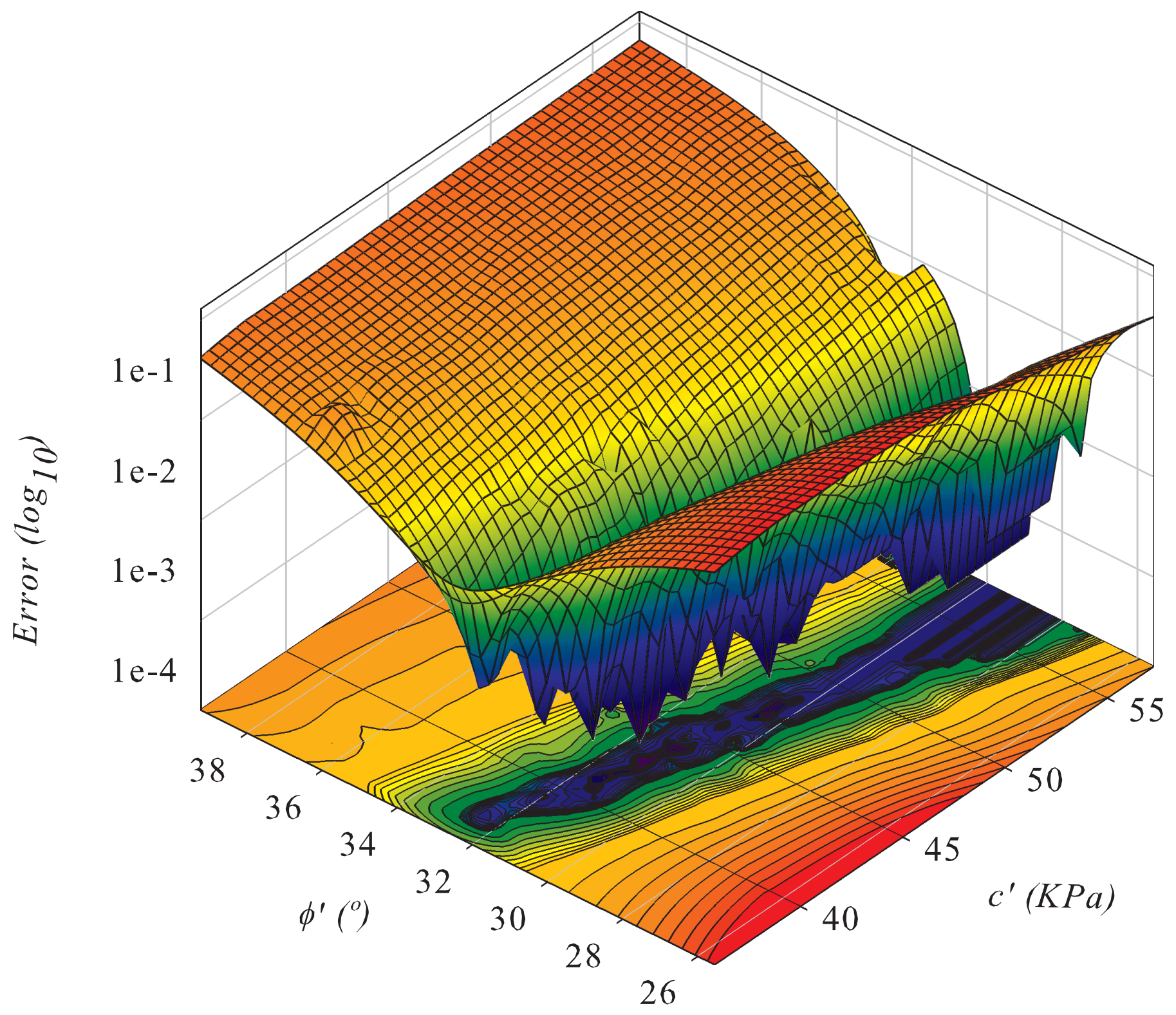

a) 


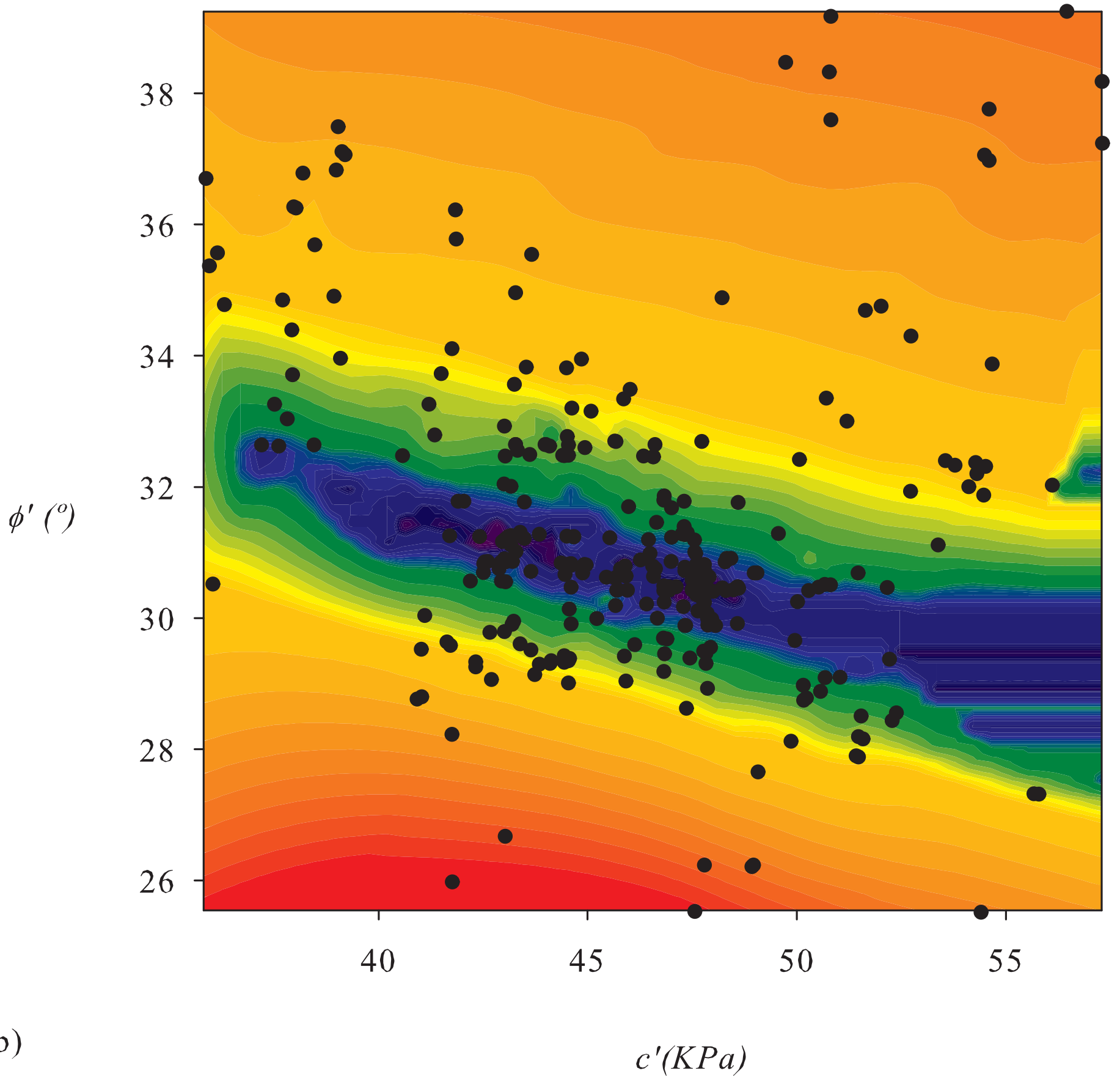




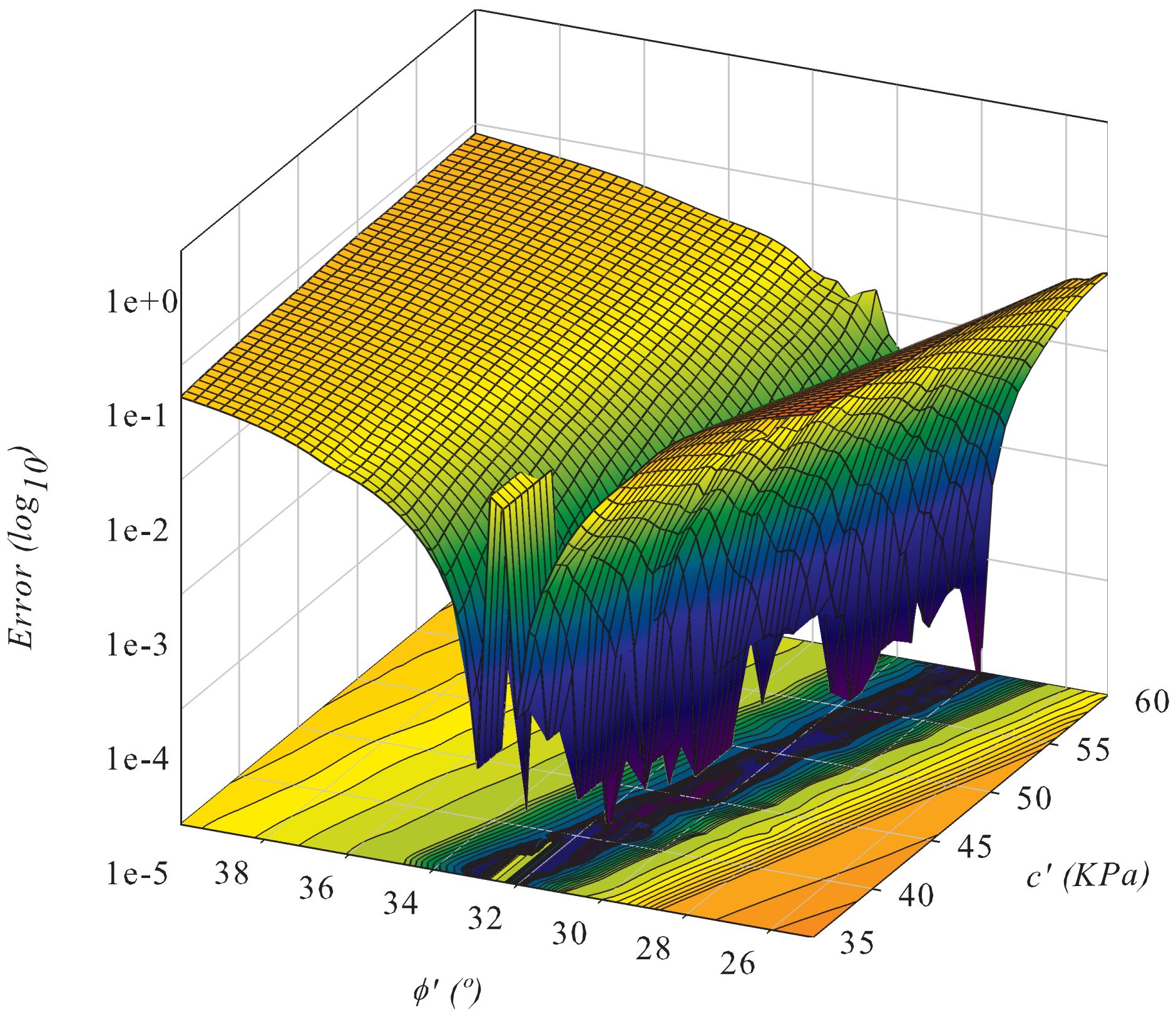

(a) 


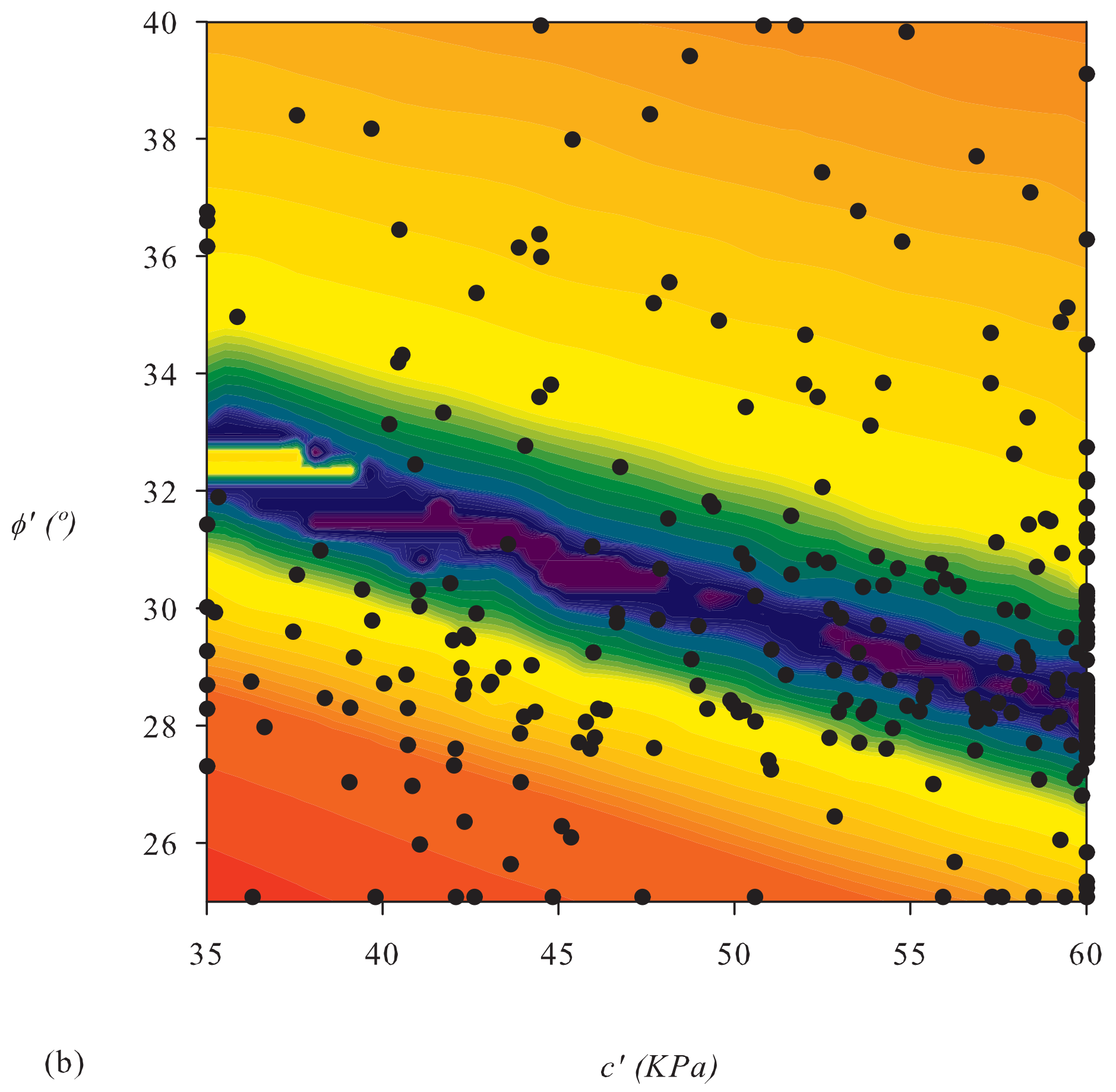




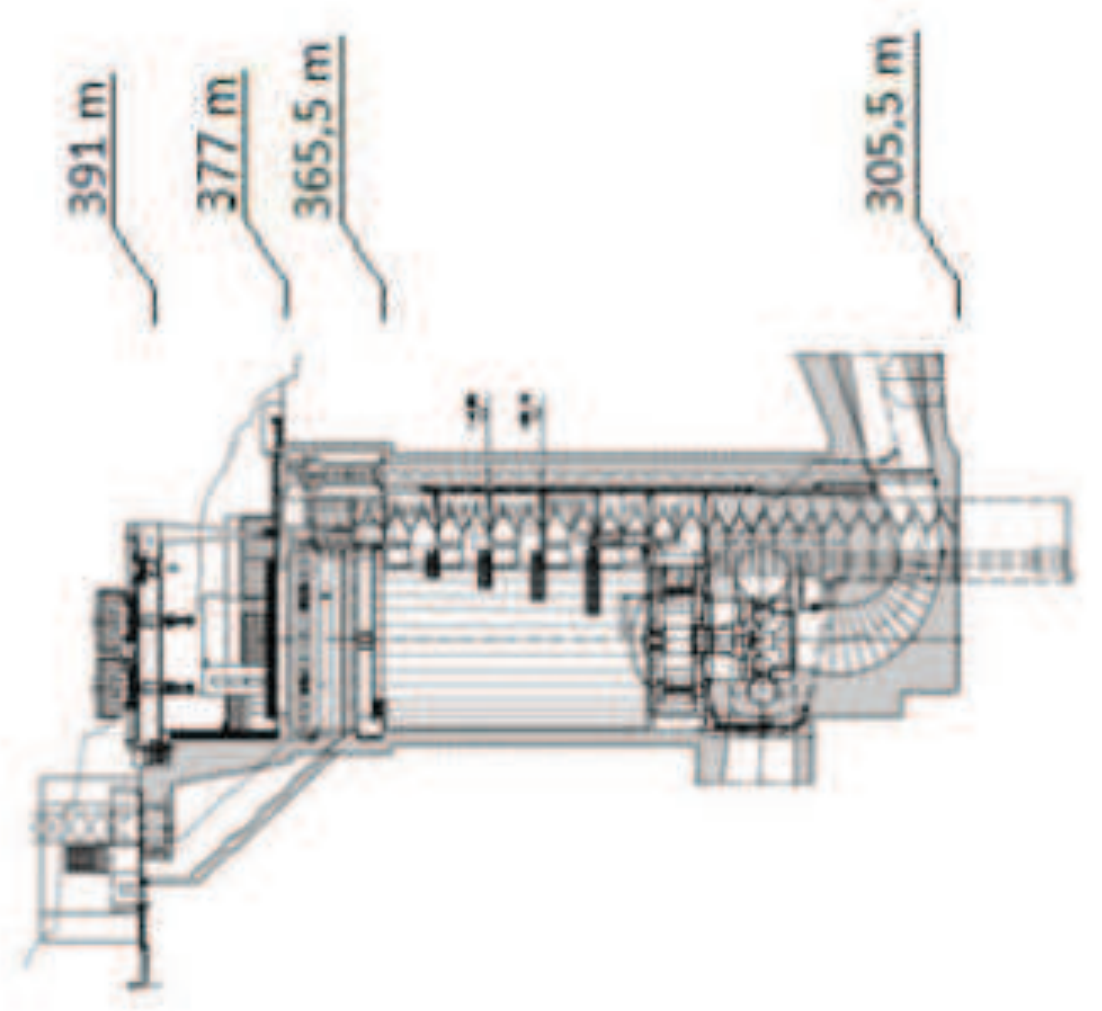

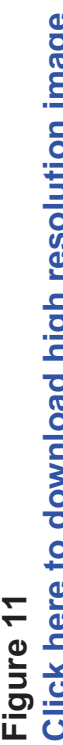

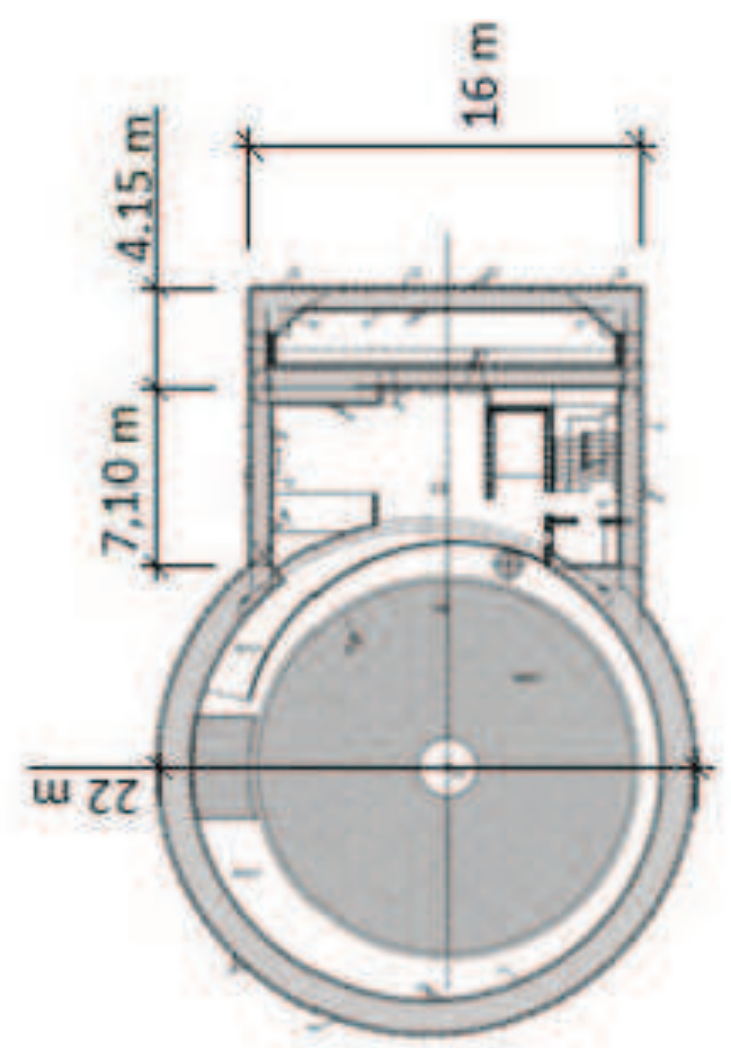




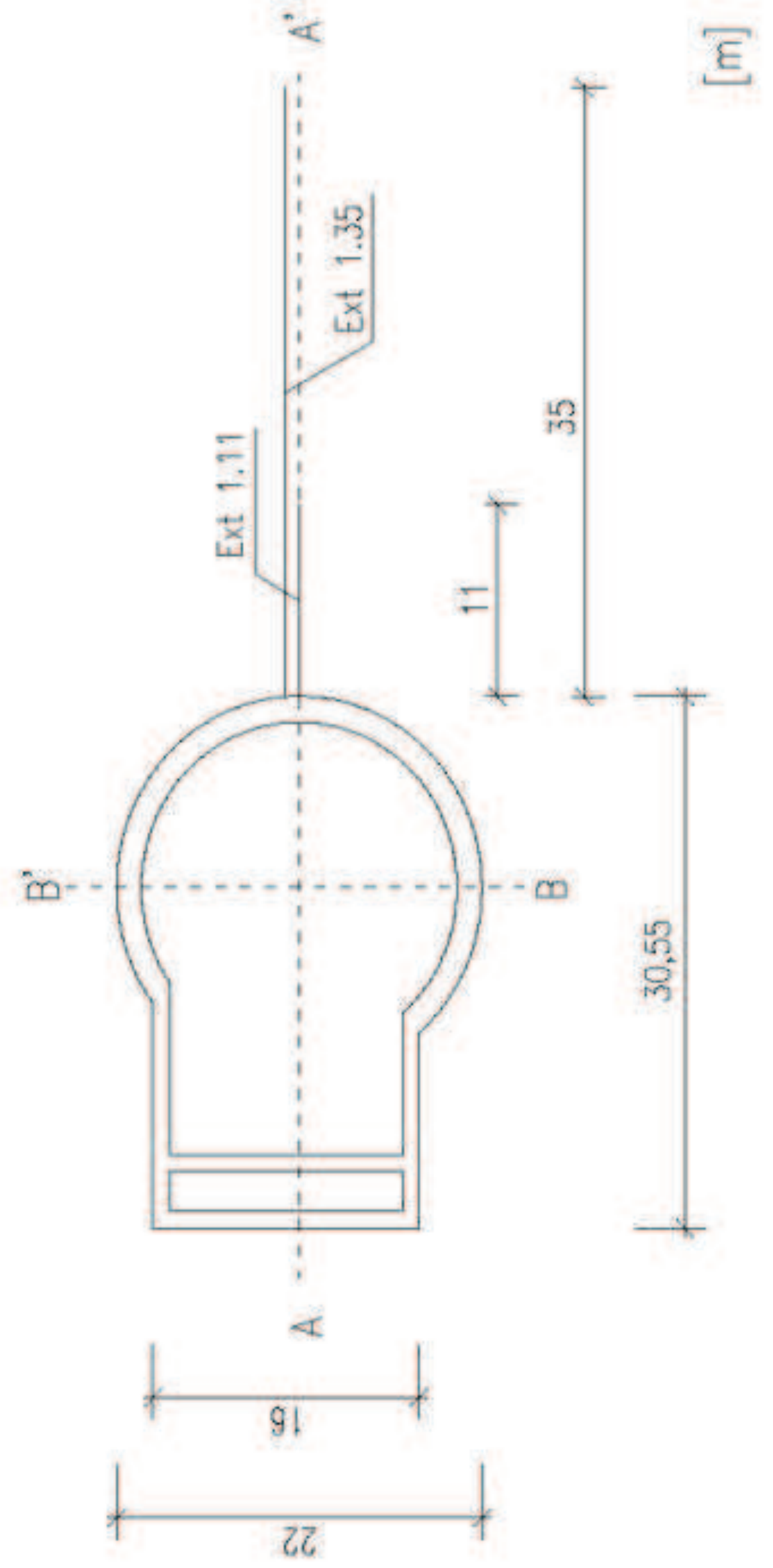

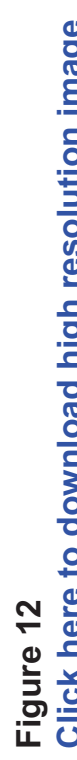




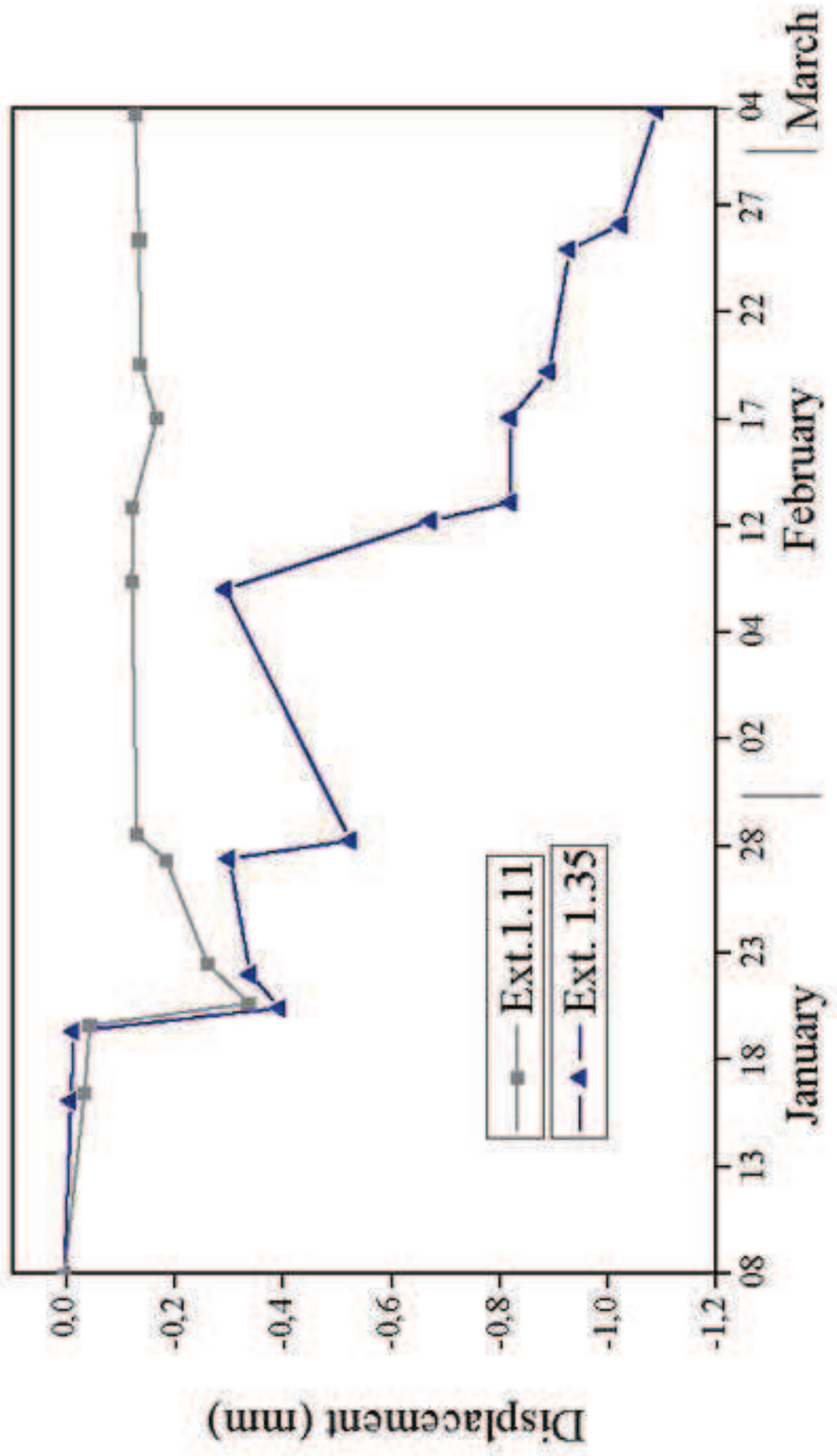

$\stackrel{ }{\circ}$

ఏ 은 

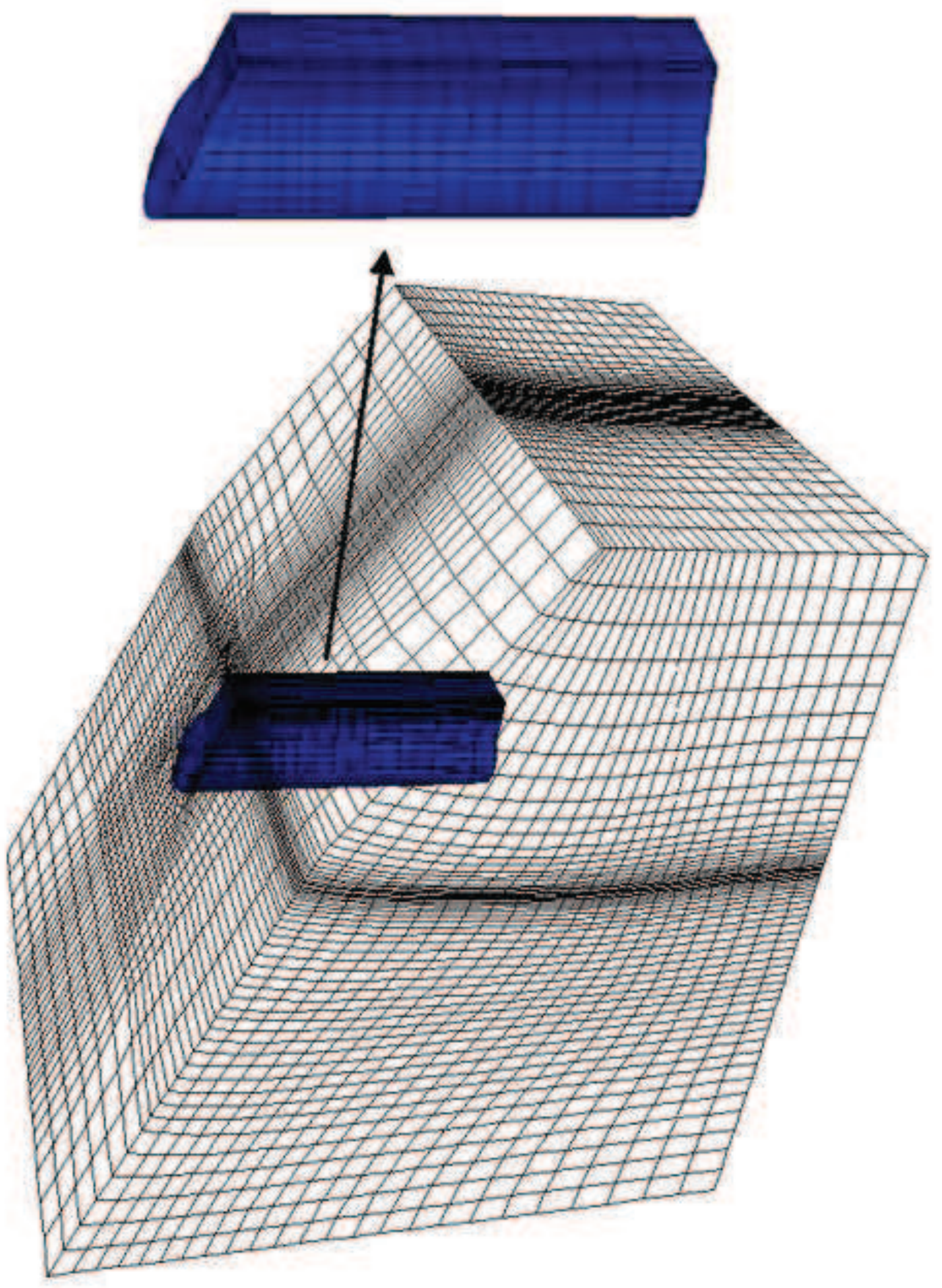
Figure 15a

Click here to download high resolution image

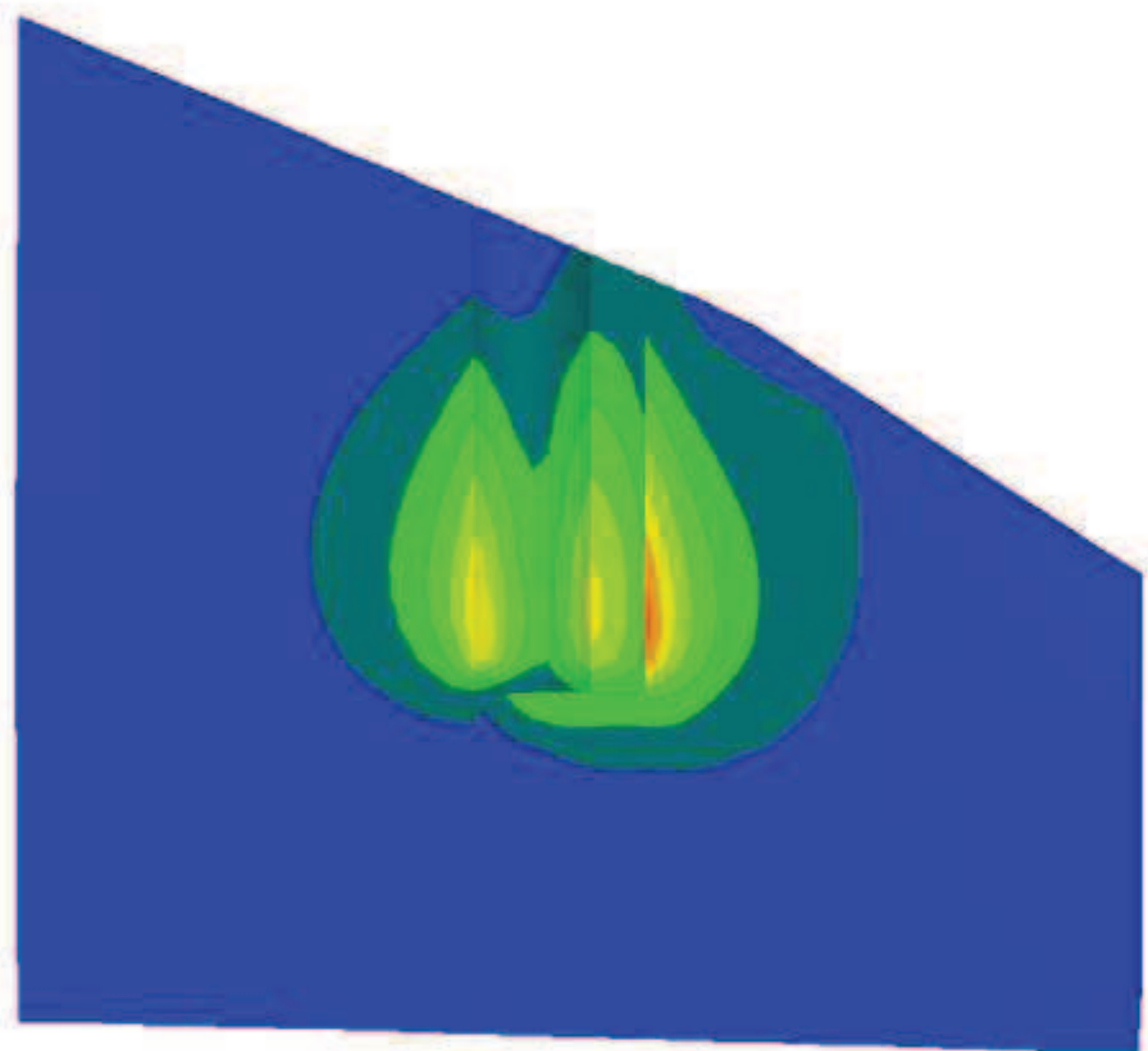

a) 


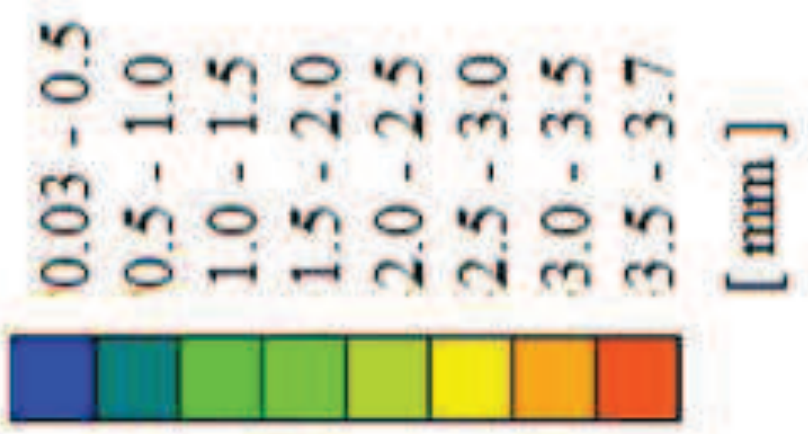

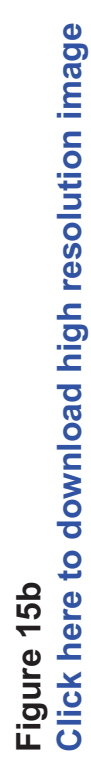

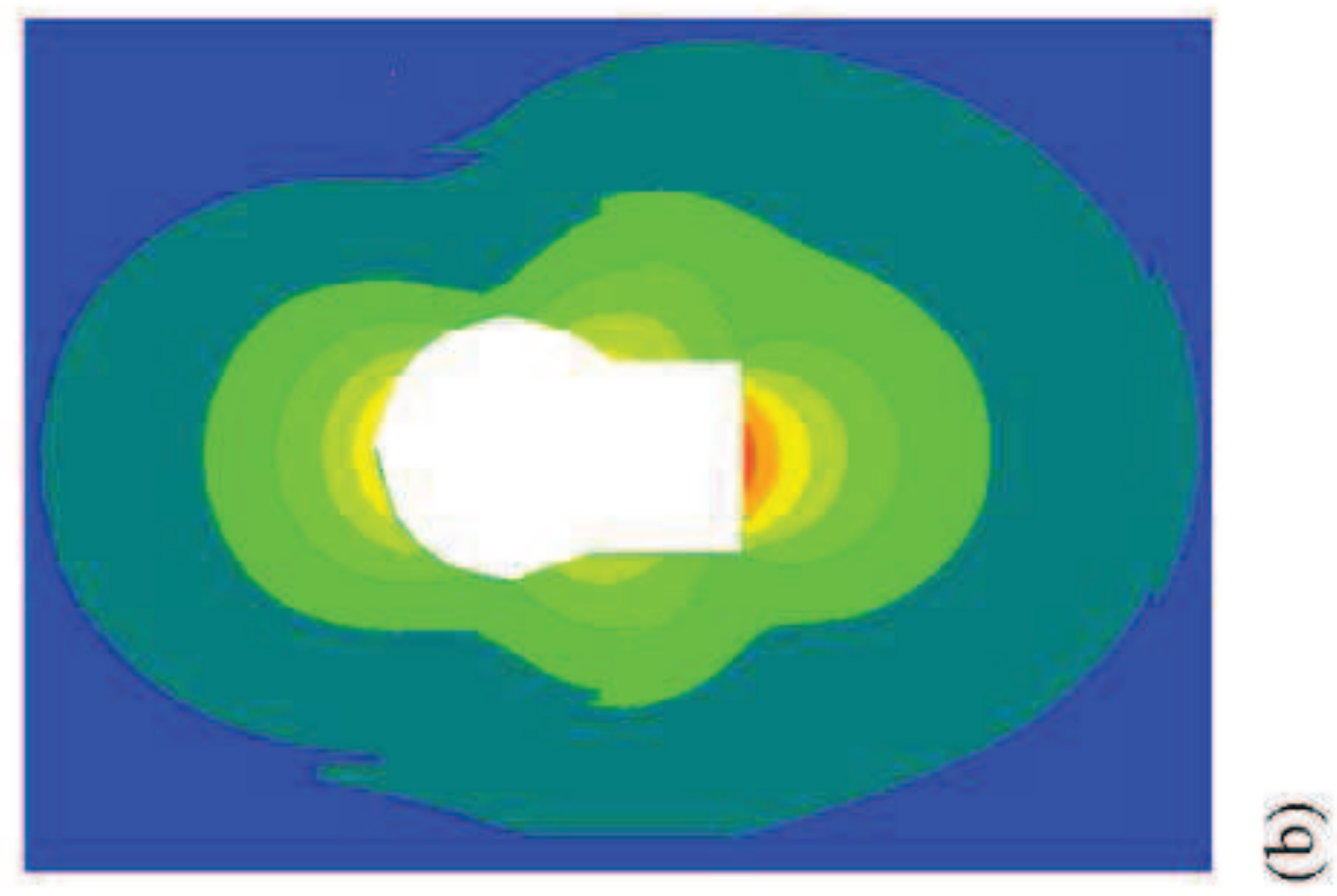




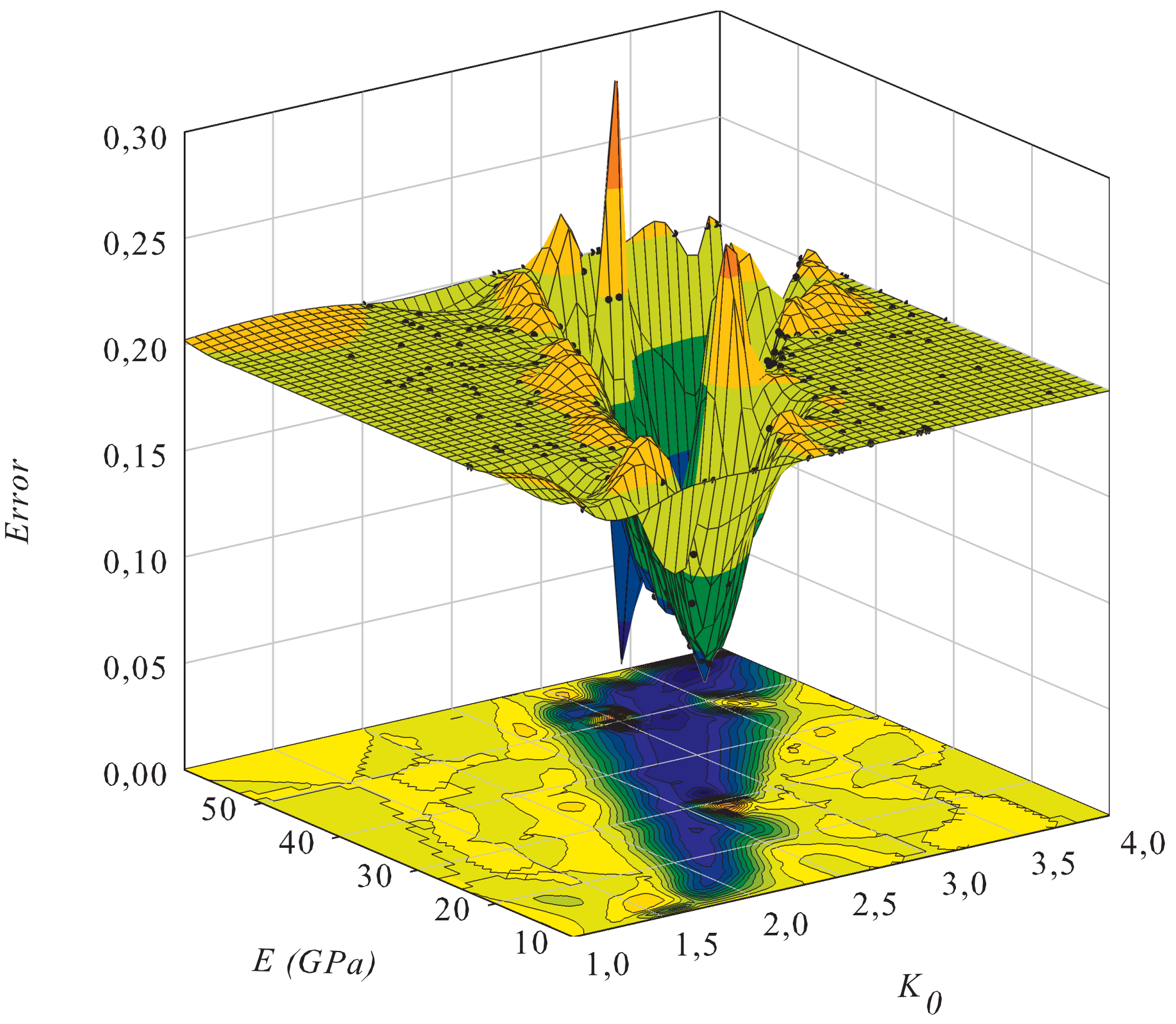

(a) 


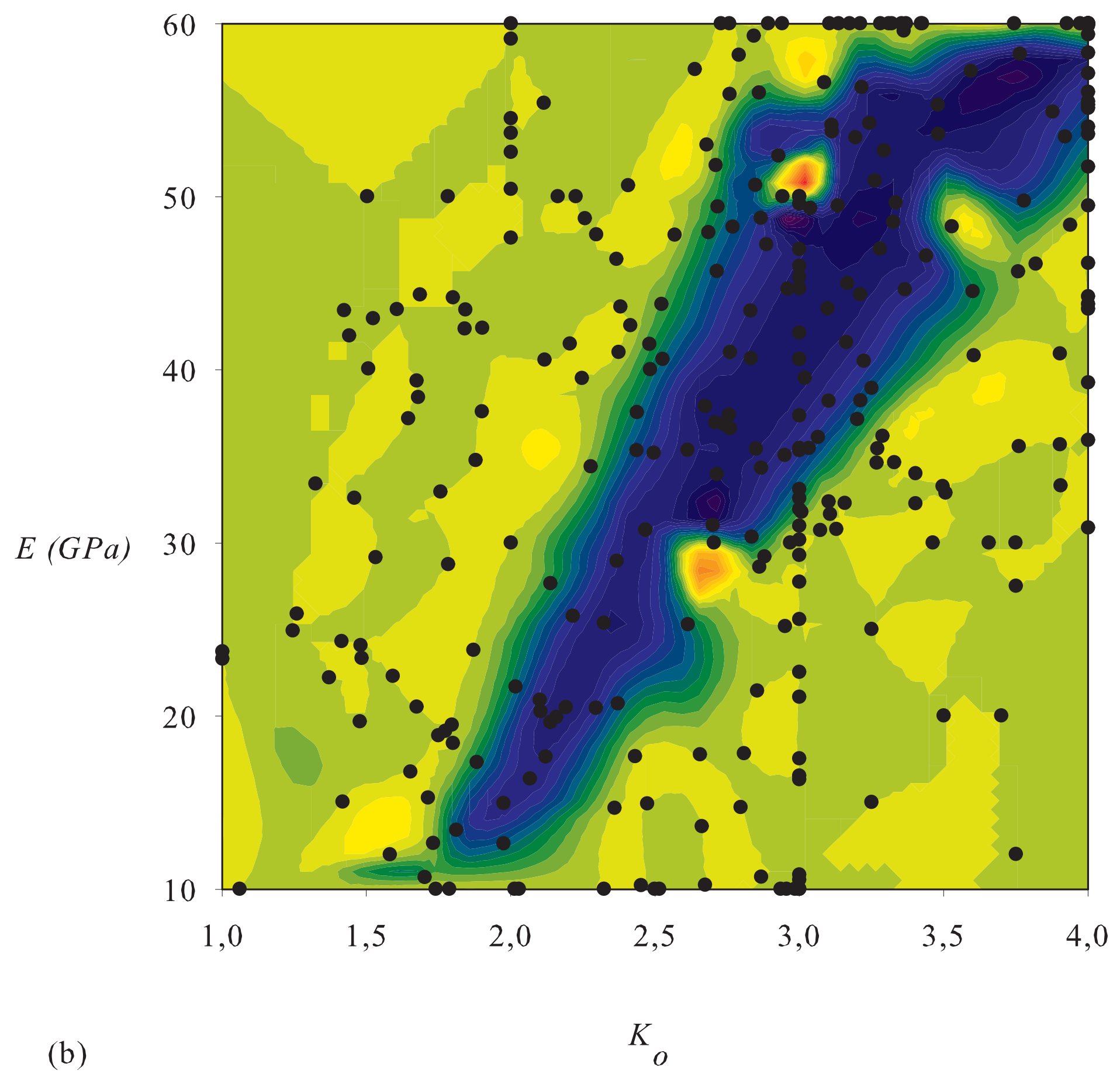




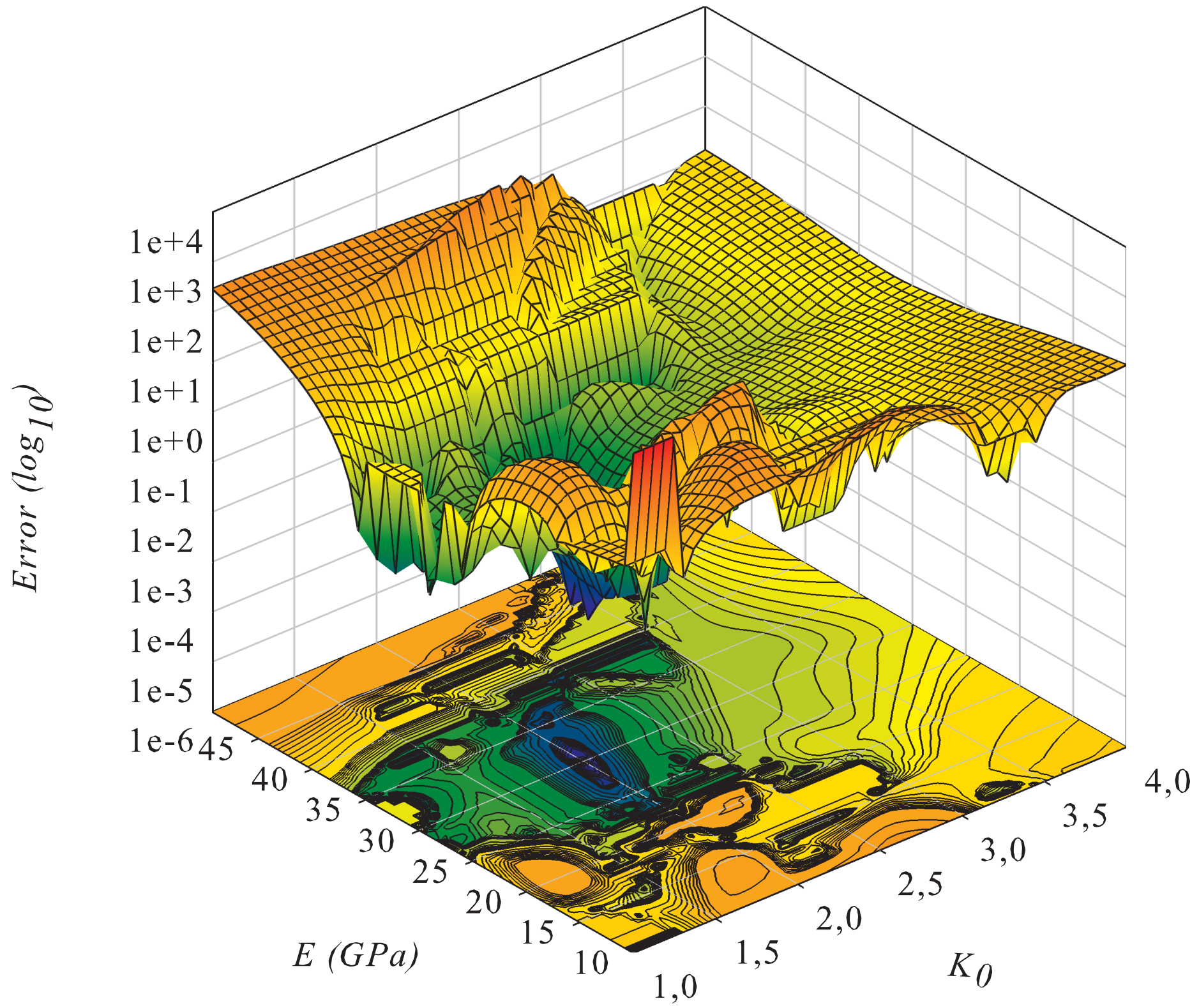

(a) 


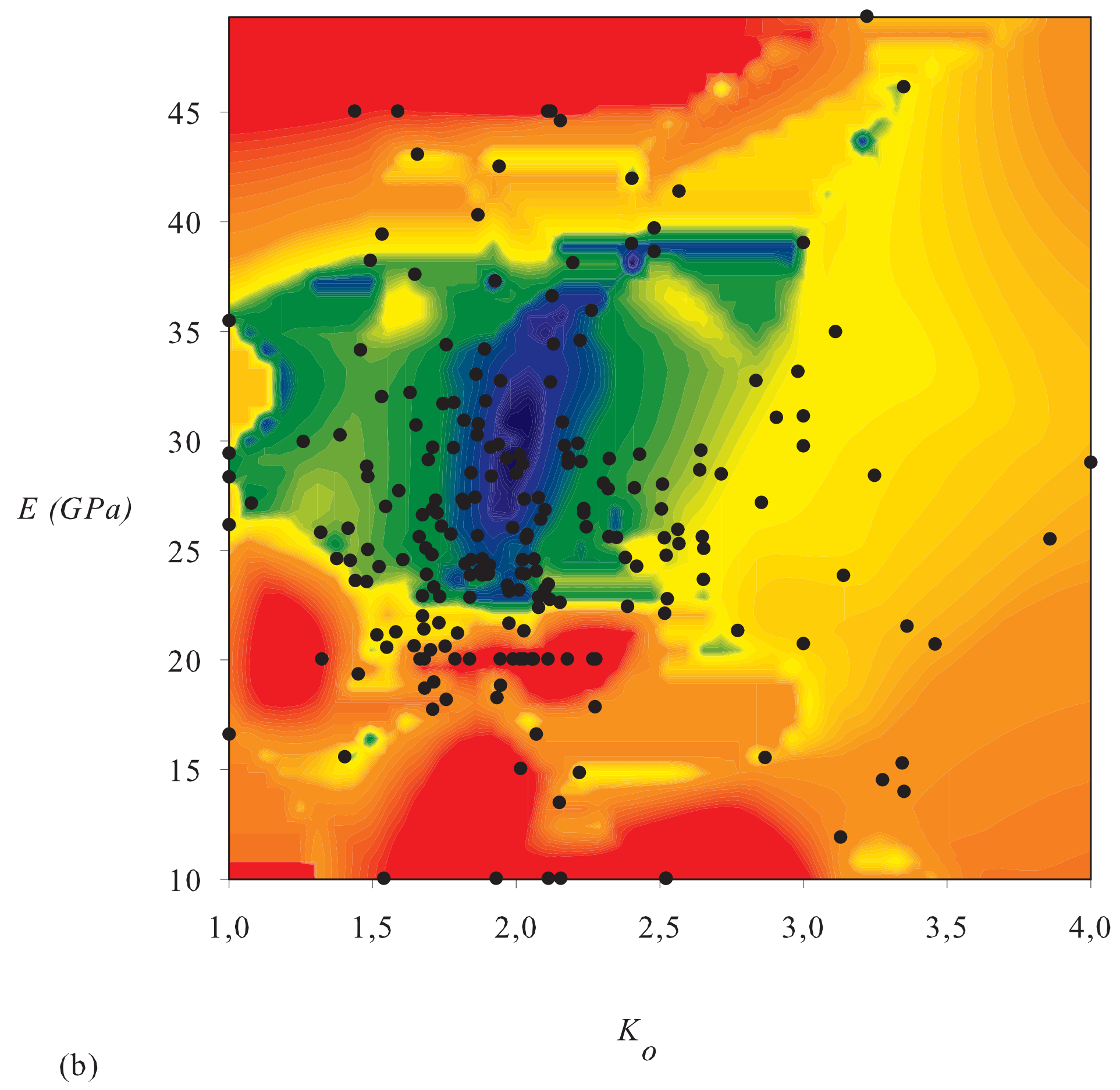




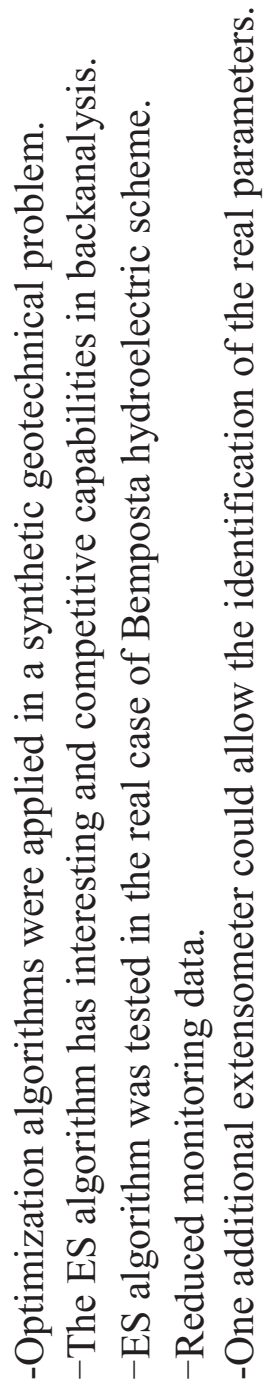

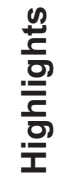




\title{
BACK ANALYSIS OF GEOMECHANICAL PARAMETERS IN UNDERGROUND WORKS USING AN EVOLUTION STRATEGY \\ ALGORITHM
}

\author{
Moreira $\mathrm{N}^{1}$, Miranda $\mathrm{T}^{2}$, Pinheiro $\mathrm{M}^{3}$, Fernandes $\mathrm{P}^{4}$, Dias $\mathrm{D}^{5}$, Costa $\mathrm{L}^{6}$, Sena-Cruz, $\mathrm{J}^{7}$
}

\begin{abstract}
The purpose of this work is to evaluate the performance of an optimization algorithm from the field of evolutionary computation, namely an Evolution Strategy, in back analysis of geomechanical parameters in underground structures. This analysis was carried out through a parametric study of a synthetic case of a tunnel construction. Different combinations of parameters and measurements were carried out to test the performance of the algorithm. In order to have a comparison base for its performance also three classical optimization algorithms based on the gradient of the error function and a Genetic Algorithm were used. It was concluded that the Evolution Strategy algorithm presents interesting capabilities in terms of robustness and efficiency allowing the mitigation of some of the limitations of the classical algorithms.
\end{abstract}

Moreover a back analysis study of geomechanical parameters using real monitoring data and a 3D numerical model of a hydraulic underground structure being built in the North of Portugal was performed using the Evolution Strategy algorithm, in order to reduce the uncertainties about the parameters evaluated by in situ and laboratory tests. It was verified that the low quantity of monitoring data available hinders the possibility to identify the parameters of interest. The existence of information of only one additional extensometer perpendicular to the existing one would allow this identification to succeed.

Keywords: Underground structures, Geomechanical parameters, Evolution Strategy algorithm 
1 Researcher, University of Minho, Department of Civil Engineering, Rua das Agras 10 4705-480 Lamas Braga, Portugal. E-mail: d5571@civil.uminho.pt Tel.: +351 918593936. (Corresponding author)

${ }^{2}$ C-TAC, Assistant Professor, University of Minho, Department of Civil Engineering, Campus de Azurém 4800-058 Guimarães, Portugal. E-mail: tmiranda@civil.uminho.pt

${ }^{3}$ Researcher, University of Minho, Department of Civil Engineering, Campus de Azurém 4800058 Guimarães, Portugal. E-mail: a51318@alunos.uminho.pt

${ }^{4} \mathrm{PhD}$ Student, University of Minho, Department of Civil Engineering, Campus de Azurém 4800058 Guimarães, Portugal. E-mail: pfernandes@civil.uminho.pt

${ }^{5}$ Full Professor, Joseph Fourier University, LTHE, Grenoble, France. E-mail: daniel.dias@ujfgrenoble.fr

${ }^{6}$ Assistant Professor, University of Minho, Department of Production and Systems, Campus de Gualtar, 4710-057 Braga, Portugal. E-mail: lac@dps.uminho.pt

${ }^{7}$ ISISE, Associate Professor, University of Minho, Department of Civil Engineering, Campus de Azurém 4800-058 Guimarães, Portugal. E-mail: jsena@civil.uminho.pt

\section{INTRODUCTION}

In underground structures, geologic and geotechnical survey is of utmost importance due to the high influence of the geomechanical parameters in the conception, design and construction processes. Normally, these parameters are evaluated by means of laboratory and in situ tests. However, uncertainties remain about their "real" values, due to factors like the chosen location of the testing points, the dimension of the involved volume and heterogeneities of the formations.

In design stage numerical models are developed in order to understand with good precision the stress/strain state and the changes provided by the excavation. Also, monitoring plans are 
established to verify if the real behavior of the structure is consistent with predictions. Using the model and monitoring data it is possible to carry out, during the construction stage, an inverse analysis process to complement the geologic and geotechnical survey and to update the geomechanical parameters used in design adapting it to the real in situ conditions.

The procedure of using field measurements in order to obtain input material parameters is called back analysis (or inverse analysis) in opposition to the conventional forward approach. A forward analysis starts with the definition of a constitutive model and its parameters which is normally carried out based on geological-geotechnical survey and in experience. This information is used as an input on the numerical models to predict stresses, strains, displacements, etc. In the back analysis approach, field measurements are used together with the models to calibrate input parameters (geomechanical, stress state, etc...) matching, under a defined tolerance, predicted with observed measures. Commercial modelling software is not prepared to compute geomechanical parameters from measurement input data, hence, an iterative procedure has to be carried out. To minimize the number of iterations and converge to the best set of parameters, optimization algorithms are used.

Classical optimization algorithms like the gradient based and the simplex have been extensively used in geotechnics to iteratively change the input parameters of the model in order to obtain the best match between measured and computed quantities [1-5]. They present a satisfactory performance in smooth-shaped error functions, with a clearly defined and unique minimum [69]. However, these problems are normally ill-posed and the uniqueness of the solution cannot be guaranteed. Moreover, they only can back analyse a reduced number of parameters (two or three) with an important influence on the computed values, i.e. it is difficult to identify parameters whose variation does not have a significant impact on the results $[10,11]$. 
Therefore, it is advisable to perform sensitivity analysis and use of a priori knowledge before the identification process, to reduce the number of parameters and search parameter space to a manageable level [1]. However, this study does not hinders the possibility of multiple solutions to the problem exist and the question of non-uniqueness remains also due to experimental and numerical uncertainties. In this sense, classical optimization algorithms present considerable limitations in back analysis of geotechnical parameters and convergence for the optimum set of parameters is not assured $[6,12,13]$.

Recently, global optimization algorithms from the field of Evolutionary Computation have been used to overcome the limitations of classical algorithms with special emphasis to the Genetic Algorithms (GA) [7-9,12-14]. These algorithms work with populations of potential solutions that evolve to better ones through processes that mimic natural selection in biological species.

Most of the works concerning back analysis in underground works use 2D numerical models. However, in many cases, important 3D equilibrium develops and should be considered in the models. This is especially true in underground caverns where the plain strain considerations considerable part from reality. In this sense, it is also important to analyze the performance of back analysis algorithms with this type of models for they raise another challenges due to the normally high computational cost of each calculation therefore they should be kept within a reasonable number to avoid prohibitive calculation times.

This work focuses on the application of a global optimization algorithm that uses an Evolutionary Computation approach, namely an Evolution Strategy (ES) in back analysis of geomechanical parameters to evaluate its performance in terms of efficiency and robustness. This algorithm is based on similar principles as the GA but has some distinctive characteristics that can be of significance importance to enhance the optimization procedure. 
A synthetic case of a tunnel excavation was developed and a parametric study was carried out. In a first stage, geomechanical parameters were attributed to the rock mass in order to obtain the "real" displacements due to the excavation process. Then, these displacements were used together with the algorithm to back analyse the parameters of interest. In order to have a comparison base also a GA and three gradient based algorithms were applied in this synthetic problem.

The ES algorithm was also used in a real case for the back analysis of geomechanical parameters of the rock mass interesting the Bemposta II power station. This is a hydroelectric scheme being built in the North of Portugal. The field measurements were provided by a double extensometer placed horizontally in a cross section of the power station and a $3 \mathrm{D}$ numerical model was specially developed for this purpose. The geomechanical parameters evaluated in the back analysis process were the deformability modulus and the stress ratio in the perpendicular direction of the riverbed because these were the parameters with highest influence in the behavior of the rock mass and also the ones with largest uncertainty degree.

\section{BACKGROUND}

Back analysis was introduced by Gioda [15], Gioda and Maier [16] and Cividini et al. [17] for the sophistication of the observational method and constitutes an essential tool for assessing design parameters in underground structures. In the broader field of geotechnics, back analysis can be found in many applications, such as: underground works $[2,15,16,18,19,20-26]$; laboratory and field tests results $[5,9,11,13,16,17,27-31]$; excavations $[1,2,7,9,12,32,33]$; and embankments [34-36].

The most common methodology of back analysis is the direct approach which is characterized by three main elements: the error function, the numerical model and the optimization algorithm. 
The error function evaluates the difference between the computed and monitored values. The most common error function is the least square equation (1) which was also used in this study.

$$
\varepsilon=\frac{1}{m} \cdot \sum_{j=1}^{m}\left[\frac{\eta_{j}-f_{j}(\hat{x})}{\eta_{j}}\right]^{2}=\frac{1}{m} \cdot \sum_{j=1}^{m}\left[1-\frac{f_{j}(\hat{x})}{\eta_{j}}\right]^{2}
$$

where, $\varepsilon$ is the mean squared error, $\hat{x}$ is the vector of $n$ components of the parameters to estimate, $\eta_{j}$ is the $j$ obtained measurement, $f_{j}$ is the computed value correspondent to the $j$ measurement and $m$ is the in situ measurement number.

The numerical model simulates the construction process and the geometry of the underground structure. Finally, the optimization algorithm carries out an iterative process computing solutions for the geomechanical parameters in order to minimize the error function. In geotechnics, two main types of algorithms have been used: iterative optimization algorithms form the field of classical optimization theory such as the Simplex, the Levenberg-Marquardt, the Newton-Raphson or gradient methods $[1,2,4,22,23]$; and optimization methods from the artificial intelligence field like neural networks (ANN), GA, ES, Simulated Annealing, etc [7$9,12-14,26,28,29,33,37,38]$.

The classical optimization algorithms are characterized by the use or not of the first, $g(x)$, and second, $H(x)$, derivatives of the error function, $f(x)$. For example: the Simplex, the Gauss method and the Rosenbrock algorithm require only the evaluation of $f(x)$; the gradient methods require the evaluation of $f(x)$ and $g(x)$; and the Newton's method use the information about $f(x)$ and $H(x)$. The performance of the optimization methods is highly dependent on the problem in which it is applied. 
In terms of limitations, these algorithms only determine a set of unique parameters and are limited to a reduced number of parameters to optimize [5]. As stated, the uniqueness of the solution is not guaranteed and since several local minima may occur the algorithm normally converges to the local minimum closer to the initial guess. To mitigate this limitation several calculations considering different sets of initial parameters can be carried out, however this procedure highly increases the computational cost. Another possible way is to use the probabilistic approach presented by Ledesma et al. [22] that considers the experimental uncertainties in order to limit the non-uniqueness of the solution. Finally, the derivatives of the error function (in relation to the parameters of interest) can be difficult to obtain mainly when numerical models are used. In most cases a finite difference technique is used to compute the derivative which means that for each iteration $n+1$ calculations of the model have to be performed, being $n$ the number of parameters to identify.

Evolutionary algorithms is a family of stochastic search techniques inspired by Darwin's theory of natural selection and survival of the fittest. They try to mimic the natural evolution of the species in biological systems $[39,40]$ and are characterized by a search of the solution in the entire parameter space. These algorithms do not require the derivatives or any continuity of the error function, only the information regarding the error function and the constraints. They start with a set of points normally generated at random, each point correspond to a possible solution (a set of parameters), that evolves over time, rather from individual to individual. These algorithms are able to localize a set of optimum solutions in complex problems which is suited for typical geotechnical back analysis problems.

Evolutionary algorithms can be divided into three main areas of research: GA, ES and Evolutionary Programming [41]. The last, which was firstly created by Lawrence Fogel in 1960, as an independent paradigm, has evolved to become very similar to the ES and nowadays they are difficult to distinguish. GA are computational models inspired by the processes of natural 
selection and genetics. They were first developed by Holland [42] at the University of Michigan and have since been applied successfully in many areas, particularly in numerical optimization problems $[43,44]$. The basic components of a GA are the population of individuals, where each represents a potential solution to the problem, the evaluation mechanism of the individuals in the population and the genetic operators that search for new solutions.

GA work on a population of potential solutions, or individuals, in which it is applied the principle of survival of the fittest, i.e., individuals compete with each other for survival. After being evaluated, the best individuals have a higher probability of being selected (for parents) and generate new individuals (offspring). The generation of new individuals is computed through mechanisms based on genetics. Thus, the offspring are generated from the recombination of the parents by inheriting some of their characteristics. Furthermore, mutation is applied with the aim of enabling the appearance of some truly innovative features. The generated offspring compete among themselves and with parents. This process is repeated over a determined number of generations $[39,43]$. Over the generations, since the best individuals are more likely to be selected to produce offspring and possibly to generate good offspring, the population tends to have increasingly better individuals. This genetic search process leads to the evolution of the population and the best individuals tend to survive, such as in natural adaptation.

GA can provide a set of satisfactory solutions therefore can be implemented to solve different types of problem $[7-9,13,14]$. In these references extensive explanation of the principles of GA are presented. Additional information on the theoretical formulation of GA can be found in a number of other references (e.g. [41-45]). 
ES algorithms emerged from Rechenberg's work in the late 1960 in Germany [46] and later extended by the work of Schwefel [47-51]. ES are more thoroughly described in the next section of the paper.

Both GA and ES are identical with respect to their major working scheme. Both rely upon the collective learning paradigm gleaned from natural evolution and implement the principles of "population", "mutation", "recombination" and "selection". However, they exhibit significant differences with respect to the details of the selection scheme, the encoding of the variables to optimize and, especially, the self-adaptation of the strategy internal parameters during the optimization process. Detailed information concerning the differences between the algorithms can be found in [45].

The before mentioned applications of these algorithms in geotechnics show that their results are very promising, mitigating and in some cases eliminating the drawbacks presented by the classical algorithms. The main limitation is that these algorithms need a substantial amount of iterations to find acceptable results, which can be, in some cases, prohibitive if large numerical models are used. However, the advances in the coding of the algorithms, more powerful and cheap computers and parallel and distributed computing can help mitigating this drawback.

\section{EVOLUTION STRATEGIES}

The ES were initially developed by Rechenberg [46] to solve optimization problems based on natural mechanisms of evolution of the species that occur in nature. In each generation, using the individuals present in the parent population, new individuals are generated constituting the offspring population. 
Like GA, the ES work with populations of candidate solutions, requiring only data based on the objective function and constraints, and no derivatives or other auxiliary knowledge. However, ES work directly with the real representation of the decision variables (in this case a set of geomechanical parameters) in which an individual is a vector of real numbers (the decision's variable) and represents a potential solution for the optimization problem. They search the solution from an initial population (a set of points) normally generated at random.

In the first and simpler ES, developed by Rechenberg [46], the selection was made in a population composed only by two members, denominated by (1+1)-ES. In this strategy, at a given generation, there are only one parent $(\mu=1)$ and one offspring $(\lambda=1)$ generated by mutation. Selection takes place between the two in relation to the error function value, provided that it satisfies all constrains. The selected one becomes then the parent of the next generation and the process is repeated until the stop criteria is met [39]. Later, the same author developed a more complex multi-member strategy where the selection was made on a population of $\mu>1$ parents and one offspring, denominated $(\mu+1)$-ES. This strategy is not widely used but it led to further enhancements [41].

Rechenberg also developed the $(\mu+\lambda)$-ES, that in a given generation, a population of $\mu$ parents generates $\lambda$ offspring by mutation. Then the $\mu$ parents plus $\lambda$ offspring are sorted according to their objective function value and finally the $\mu$ parents used in the next generation are the best individuals of the $\mu$ parents plus the $\lambda$ offspring (i.e., the selection takes place between the $\mu+\lambda$ members) (Figure 1). The $(\mu, \lambda)$-ES is similar to the $(\mu+\lambda)$-ES except in the way the selection of the $\mu$ parents used in the next generation is carried out. In this case, the $\mu$ parents are selected from the best individuals of $\lambda$ offspring (i.e., the selection takes place between the $\lambda$ members).

Mutation is a genetic operator that creates new points by adding random normal distributed quantities $z^{(k)}$ with mean zero and variance $\sigma_{i}^{2}$ to the parent (vector of decision variables) in a 
process called Gaussian mutation. It is important to note that, for each decision variable, an individual standard deviation $\sigma_{\mathrm{i}}$ can be used (controlling the step sizes).

The initial standard deviations for mutation $\sigma_{i}$ can be set using equation 2 .

$$
\sigma_{i}^{(0)}=\frac{\Delta x}{\sqrt{n}}
$$

where $\Delta x$ is a rough measure of the distance to the optimum and $n$ is the problem dimension. However, it can be difficult to estimate $\Delta x$, therefore the alternative equation 3 can be used.

$$
\sigma_{i}^{(0)}=\frac{\beta_{i}-\alpha_{i}}{\lambda \sqrt{n}}
$$

where $\alpha_{i}$ and $\beta_{i}$ are the lower and upper bounds of the decision variable $i$.

During the search, the standard deviations (or step sizes for mutation) are adapted and this is one of the most promising features of the ES. They are updated during the process using different rules and self-adaptation schemes which enhance the algorithm performance [52]. Several self-adaptation schemes are possible. For the non-isotropic mutation, where the adopted standard deviations are different for each variable, one possibility is to update these standard deviations $\sigma_{\mathrm{i}}$ according to the equation:

$$
\sigma_{i}^{(k+1)}=\sigma_{i}^{(k)} e^{z_{i}} e^{z}
$$

where $z_{i} \sim N\left(0, \Delta \sigma^{2}\right), z \sim N\left(0, \Delta \sigma^{2}\right)$ which means $z_{i}$ and $z$ follow a normal distribution with 0 mean and $\Delta \sigma$ and $\Delta \sigma^{2}$ representing their variance, are parameters of the algorithm.

Originally, the ES was based only in one operator, mutation, to generate the new individuals. Later, Schwefel [50] has reported a remarkable acceleration in the search process, as well as, the 
facilitation of self-adaptation of parameters by introducing a recombination operator. Basically, it consists on, before mutation, to recombine a set of chosen parents to find a new solution (Figure 1). A given number $\rho(1 \leq \rho \leq \mu)$ of parents are randomly chosen for recombination. When $\rho=1$ then there is no recombination. Thus, the nomenclature for the ES can now be extended, and ESs with recombination are usually referred as $(\mu / \rho+\lambda)$-ES or $(\mu / \rho, \lambda)$-ES.

There are two main types of recombination, namely intermediate and discrete. In the intermediate recombination, the components of the offspring are obtained by calculating the average of the corresponding components of parents (randomly selected from the population). In the discrete recombination, each component of the offspring is chosen from one of the $\rho$ parents at random.

In the present study a $(\mu / \rho+\lambda)$-ES was used. The main characteristics of the algorithm are resumed in Table 1. The stopping criterion for both the GA and the ES was set as a maximum number of calculations, in this case 300. This criterion was adopted for two main reasons: it was intended to check the efficiency of the algorithms, so the maximum number of calculations was kept within a reasonable amount to evaluate the quality of the results with a few hundred of calculations and also to provide manageable computation times; and as it was intended to obtain the topology of the error function with good precision some hundreds of points were needed so the calculations should not stop as soon as a certain error was obtained since it could be due to a local minimum and the error function would be incomplete.

\section{PARAMETRIC STUDY OF BACK ANALYSIS}

\subsection{Back analysis procedure and numerical model}


The parametric study of back analysis was carried out through the application of the ES algorithm to the identification of geomechanical parameters in a synthetic case of a tunnel excavation using a 3D numerical model [26,53]. For comparison sake, also classical optimization algorithms based on the gradient of the error function, namely the steepest descent (SD), the conjugate gradient (CG) and the quasi-Newton $(\mathrm{QN})$ algorithms, as well as a GA were also used. The algorithms were programmed in Matlab 7.9 [54] and connected to the numerical model to perform the iterative process.

The numerical model for the synthetic case was developed with FLAC3D [55] and it is a $20 \mathrm{~m}$ length tunnel composed by a $4 \mathrm{~m}$ radius arch and a vertical wall with the same span. It is composed by 1110 zones and 1375 grid-points (Figure 2). The support system consists of $0.2 \mathrm{~m}$ thick shotcrete simulated by shell elements with linear elastic isotropic behaviour, with a Young modulus of $20 \mathrm{GPa}$ and a Poisson ratio of 0.2 .

The construction process begins with the excavation of the tunnel arch in a $3 \mathrm{~m}$ length followed by the application of the shotcrete on the arch, then the remaining part of the tunnel is excavated and finally the shotcrete is applied in the walls of the tunnel.

The mass surrounding the tunnel was simulated as an equivalent continuous. In a first stage, an elastic constitutive model is used. The values of the initial geomechanical parameters used to produce the "real values" of the monitoring data were the following: deformability modulus $(E)$ of $2 \mathrm{GPa}$ and a Poisson coefficient of 0.1. A gravitational stress state was considered with a horizontal to vertical stress ratio $\left(K_{0}\right)$ of 0.8 in both horizontal directions. In a second stage, calculations were performed to identify the strength parameters of the Mohr-Coulomb failure criterion with non-associated flow rule. The adopted values for cohesion $\left(c^{\prime}\right)$ and friction angle $\left(\phi^{\prime}\right)$ were, respectively, $50 \mathrm{kPa}$ and $32^{\circ}$. The low values of the strength parameters were set in 
order to induce considerable yielding zones in the model to check the influence of increased non-linearity of the back analysis process in the behaviour of the algorithms.

\subsection{Results}

\subsubsection{Gradient algorithms}

As already stated, the analysis started with the definition of a set of geomechanical parameters to obtain the "monitored" measures in a reference section. The monitored section is located near the middle of the excavation. Then, different perturbations were applied to the parameters to check if the algorithms were able to identify the real values. These perturbations were translated by summing or subtracting a given quantity to the real values and are represented by the signs $(+)$ and (-), respectively.

In the elastic model calculation, a total of five measurements in the reference section were considered through different combinations, namely: vertical displacements at the surface, at the top of the arch and in the tunnel floor; and horizontal displacement and horizontal stress perpendicular to the tunnel axis in the middle point of the wall (Figure 3). In each case, the back analysis process was carried out until the value of the error function was below a pre-defined threshold that in this case was set to $0.1 \%$

In a first stage, only the SD algorithm was used. In the first calculation two vertical displacements (surface and crown) were used in order to identify both $E$ and $K_{0}$ (cases GB_1 to GB_4). Table 2 resumes the overall results. In this case, convergence is reached in a reduced number of calculations but not for the correct values. Figure 4 shows the topology of the error function for this case where a considerable number of local minima can be observed. Moreover, 
there are an endless number of possible combinations for the parameters which lead to approximately the same error value. The non-uniqueness of the solution is due to the high correlation between the two measures (two vertical displacements) so the problem is "ill-posed" since this situation is similar to the use of only one measure to identify two unknown parameters.

Calculations were repeated replacing the vertical measurement at the surface by the horizontal displacement in the wall of the tunnel (cases GB_5 to GB_8). Table 3 presents the obtained results. In three cases convergence was achieved for the correct parameters. The results show that it may be possible to proceed with back analysis using only a few displacement measurements provided that they do not have a high correlation degree.

Still considering displacement-based back analysis, in cases GB_9 to GB_14 calculations were performed using more measurements than parameters to identify. In the process, three measures were used, namely the vertical displacements in the arch and floor and the horizontal displacement in the wall. A fourth measure was then added - the surface vertical displacement in cases GB_15 and GB_16 to analyse the effect of the input of a highly correlated measure. The results are presented in Table 4.

The results show that using three displacements, the identification process is stable and convergent and the "real" values were identified in a relatively reduced number of calculations. Figure 5 shows the topology of the error function for this case (the dots in the Figure represent the pairs of parameters tested in all iterations). It is a convex-shaped surface with a clearly defined minimum correspondent to the optimum set of parameters. Gradient-based algorithms normally show good performance in optimisation problems with these characteristics.

Comparing with cases GB_5 to GB_8, where two displacements were used, the use of more measurements leads to a more time consuming process (more calculations needed to match all 
the displacements). However, the process is more robust since convergence was reached in cases GB_12 and GB_16 which were similar to case GB_8 that did not converged.

The performance of the three algorithms was compared through several simulations, considering the measurement of one vertical displacement (tunnel arch) and one horizontal stress (tunnel wall) with different initial deviations. The results of the simulations are resumed in Figure 6.

With exception of one calculation, every case converged to the "real" parameter values. Only for a $100 \%$ deviation in both parameters, the identification process with the QN algorithm provided a negative value for $K_{0}$. This problem is not very relevant since so high deviations are not expected to happen often in practice.

In relation to performance, i.e., the number of calculation required to achieve convergence, the algorithms present slight differences. The CG algorithm showed to be the most efficient in the tested cases. In a total of seven, only in two cases the CG algorithms was outperformed. It took a mean of 15.6 calculations to converge while the SD and QN algorithms needed 18.1 and 16.5 calculations, respectively.

In the calculation using the Mohr-Coulomb constitutive model, a total of four measurements were used in different combinations, namely two displacements and two stresses (one horizontal and one vertical for each).

Several identification processes were carried out to identify the strength parameters of the Mohr-Coulomb failure criterion $\left(c^{\prime}\right.$ and $\left.\phi^{\prime}\right)$ under different conditions. Using the three algorithms, simulations were carried out considering different deviations and a variable number of available measurements. Table 5 resumes the results. 
In five out of twelve calculations the process did not converge and even in the cases convergence was obtained, the identified parameters are relatively different from the "real" ones. This tendency is more pronounced for $c^{\prime}$. This is due to the presence, in the parameter space, of local minima and low convexity of the error function. In this situation, it is expected that gradient-based algorithms perform poorly. In fact, non-convergence in several cases may be related with the flatness of the error function. In the cases where convergence was achieved, the identified parameters corresponded to the local minimum nearer the initial solution. The number of observations did not change substantially the final values of the parameters. The QN algorithm never reached convergence while for the case of the CG only in one case it was attained. In conclusion, these algorithms showed a poor performance in elasto-plasticity.

\subsection{ES and GA}

The monitoring plan set in this theoretical example was composed by the same displacement measurement considered in the previous test using the gradient-based algorithms. In the parametric study, several cases were analysed in order to evaluate the capabilities of the algorithms in different conditions (Table 6).

To use this type of algorithms it is necessary to define a variation range of each geomechanical parameter to confine the search space. For the elastic case three variation ranges were set. For the elasto-plastic model only one variation range of each geomechanical parameters was adopted to limit the computation effort.

For the elastic model the influence of the number and location of measurements was evaluated. For case EA_1, correspondent to cases GB_15 and GB_16, four displacement measurements were considered and results are shown in Table 7. The ES and the GA converged to the "real 
values" regardless of the interval range of the parameters and the performance of both algorithms is very similar. The topology of the error function presents an almost convex configuration, in which the global minimum correspondent to the optimal solution is clearly defined (Figure 7). This configuration turns convergence faster and easier for the algorithms. In cases GB_15 and GB_16 also convergence to the optimum set of parameters was obtained due to the configuration of the error function.

In cases EA_2 to EA_4 only two measurements were considered. Cases EA_2 and EA_3 use vertical and horizontal displacements while case EA_4 represents the worst case scenario of using two measurements with the same direction. The results are presented in Table 8 .

Both algorithms converged for the "real" solution in cases EA_2 and EA_3 for every range of the parameters. Case EA_2 corresponds to cases GB_5 to GB_8 and in the last case convergence problems were detected, therefore the evolutionary algorithms were able to avoid this problem. Case EA_4 corresponds to cases GB_1 to GB_4 and as seen, in these cases, the algorithms have to deal with problems concerned with the non-uniqueness of the solution. In case EA_4 the solutions slightly parted from the "real" values mostly in the wider ranges. However, the computed values can still be considered acceptable in an engineering point of view.

The topology of the error function for cases EA_2 and EA_3 are similar to the one obtained in case EA_1 and is characterized by a convex configuration in which the global minimum correspondent to the optimal solution is clearly defined. On the other hand, in case 4 this topology is much more irregular and presents several local minima as observed in Figure 4, which explains the higher difficulties of the ES and AG to identify the "real" values. These irregularities occur due to the use of two highly correlated measures, so as stated before the problem is "ill-posed". In Figure 4 it can be observed the existence of a range of parameters that 
practically conduct to the same error function value. Nonetheless, and even though the complex topology, the algorithms were able to identify values not far from the correct ones.

Using the elasto-plastic model, the complexity of the study significantly increases due to the introduction of the non-linearity given by yielding zones forming in the surrounding formation which will affect the displacements. The goal was to identify the $E, c^{\prime}$ and $\phi^{\prime}$ (at once or in combinations of two) using different number of measurements.

In cases EA_5, EA_9 and EA_11 it was intended to identify the three parameters. Table 9 shows the results for these cases. The GA converged to the optimal solution in all cases demonstrating high robustness. The ES presented similar behaviour excepting for the cohesion parameter for which the identified values presented some deviation in relation to the correct one. In the worst case an error of approximately $22 \%$ was observed. This problem could be solved performing a higher number of calculations which would enhance the quality of the solution but also increase computational cost.

Due to the number of parameters (three) in these cases the plot of the error function is not straightforward because only two parameters can be represented at the same time. The topology of the error function is represented using combinations of two parameters for case 5 (Figure 8). The error function presents a very complex topology with several local minima regardless the chosen combination of parameters. Nonetheless, the algorithms were able to mitigate these difficulties in most of the cases.

Cases EA_6, EA_7 and EA_8 consider combinations of the two geomechanical parameters with four displacement measurements while in case 10 it was intended to identify $\phi^{\prime}$ and $c^{\prime}$ using only two measurements. The results of these cases are presented in Table 10. Both algorithms 
converged to parameter values very near to the "real" ones. The only exception is slight deviations for $c^{\prime}$ showing that this is the most difficult parameter to identify probably due to a lower influence or a more complex relation with the measured displacements that leads to higher irregularities in the error function topology.

Figure 9 shows the topologies of the error function for case EA_8 (cases EA_6 and EA_7 are similar). It can be observed a linear relation between the two strength parameters corresponding to an almost constant error function value. This "valley" in the error function crosses the point that represents the optimal solution and in this line several local minima exist which difficult convergence.

Figure 10 shows the topology of the error function for case 10. Comparing this topology with the ones of the previous cases it can be concluded that the definition of the global minimum decreases with the reduction on the number of measurements and the topology presents a higher number of local minima increasing the convergence difficulties. This fact explains the higher problems in the identification of cohesion in this case.

\subsection{Discussion of the results of the synthetic case}

As concluded in previous studies (e.g. [12]) the gradient-based algorithms have a satisfactory performance, both in terms of convergence and efficiency (i.e. number of iterations needed to converge) in elasticity when the error function is strictly convex and presents a single local minimum. This issue is related also with the type and number of measurements used in the back analysis process since when using a limited number of highly correlated measurements the uniqueness of the solution may be compromised. In elasto-plasticity the problem becomes more complex due to the increased non-linearity due to yielding zones forming near the excavation. 
In this situation the algorithms performed poorly since the error functions present very complex topologies.

Both algorithms from the field of evolutionary computation showed to be very robust algorithms even for highly complex error functions. The results for the elastic case showed that the algorithms were able to identify the correct values of the parameters in almost every case even for very large interval ranges, translating the situation of high geotechnical uncertainty and in a manageable iteration number. The use of four measurements or only two with low correlation did not affect the results showing that with these algorithms it is possible to identify the elastic parameters with a very small amount of measurements. Only for the case of using two highly correlated measures the algorithms converged to slightly different values due to the high complexity of the error function but performed much better than gradient-based algorithms in the same situation.

Also in the elasto-plastic case both the GA and the ES presented similar behavior in terms of robustness and efficiency. More difficulties arose in the identification of cohesion probably due to a lower influence or more complex relation with the measured values. However, they were able to achieve very good results, regardless the high complexity of the problems, the presence of many local minima and the use of a low number of measurements.

Moreover, this was achieved in a manageable number of calculations. This was a major issue in the past since evolutionary algorithms normally took thousands of calculations to converge which meant that with highly complex numerical models, they could lead to prohibitive computation times. These more advanced versions were able to achieve good results in a few hundred calculations which make them more suited to be used together with $3 \mathrm{D}$ numerical models especially when using powerful computers complemented by parallel and distributed processing. 
This type of algorithms allow to obtain a set of solutions with approximate values of the error function which in this case form a valley on the error function as seen in Figure 4. This valley, which will translate in real cases considerable uncertainties on the definition of the most suited set of parameters, can be mitigated with the use of a more thorough monitoring plan or, if this is not possible, by a post-treatment of the solutions allowing for a more restrict definition of possible sets of values as proposed by $[8,9]$.

\section{BEMPOSTA II POWER STATION - BACK ANALYSIS OF GEOMECHANICAL PARAMETERS}

\subsection{Description of the hydraulic scheme}

For the power reinforcement of the Bemposta hydroelectric scheme, located in the North of Portugal at the international stretch of Douro river, the EDP (Electricity of Portugal) company decided to build a new 191 MW hydroelectric complex named Bemposta II.

The power plant of Bemposta II is composed by a vertical shaft excavated from the surface of the slope adjacent to the Bemposta dam [56]. The excavation begins with a rectangular section, approximately $11 \mathrm{~m}$ depth, followed by an excavation with a circular cross-section with $22 \mathrm{~m}$ diameter and approximately $60 \mathrm{~m}$ deep. The circular cross section has a rectangular extension with horizontal dimensions of $16 \times 8.75 \mathrm{~m}^{2}$ (Figure 11).

In order to characterize the rock mass in the area of the power station, 26 subvertical boreholes (with a total of $1012 \mathrm{~m}$ drilled) with 183 Lugeon permeability tests were carried out [57]. The in situ campaign consisted on 19 dilatometric tests and 6 small flat jacks tests (SFJ) and 5 stress tensor tube (STT) tests for the determination of the state of stress [58]. The results showed that 
the horizontal stress in the direction AA' (Figure 12) is approximately 2.0 times higher than the vertical one. In the direction $\mathrm{BB}^{\prime}$ the stress is approximately equal to the vertical one.

The laboratory tests consisted in 18 shear tests on joints, 31 uniaxial compressive, 64 triaxial, 106 diametral and 96 ultra-sound tests. The in situ characterization and the laboratory tests performed on the recovered samples allowed the identification of four geomechanical zones (Table 11).

The Bemposta II repowering scheme is located in highly metamorphosed heterogenous rock formations. The most part of the headrace tunnel was excavated in micaschist and migmatite while the powerhouse shaft and the tailrace tunnel, in good quality gneissic granite belonging to geomechanical zone ZG1 [57].

Monitoring of the powerhouse shaft construction was carried out by two horizontal double-rod extensometers (EV1 and EV2) and $10 \mathrm{~m}$ spaced convergence sections throughout the shaft height.

EV1 was anchored $11 \mathrm{~m}$ and $35 \mathrm{~m}$ (extensometers 1.11 and 1.35) into the rock mass from the excavation wall and it is located at level $367.5 \mathrm{~m}$ (Figure 12). The second rod-extensometer (EV2) was installed at elevation (337.00), slightly above the turbine floor. EV2 has fixed points $10 \mathrm{~m}$ and $32 \mathrm{~m}$ from the excavation wall. This extensometer was placed almost at the end of the excavation process. Therefore, the measured displacements were very low and could not be included in the back analysis process.

The measurements of the extensometer EV1 are presented in Figure 13. The maximum monitored displacements were $0.33 \mathrm{~mm}$ and $1.02 \mathrm{~mm}$ respectively for extensometers 1.11 and 1.35 . 
In order to reduce the uncertainties related to the real values of the parameters, a back analysis study of geomechanical parameters was carried out, using a 3D model of the power station, together with the ES optimization algorithm and real monitoring data from extensometer EV1. Due to the reduced amount of monitoring data, back analysis in this case will raise considerable problems of non-uniqueness and the algorithm will be tested in difficult conditions.

\section{$5.2 \quad$ Numerical Model}

The 3D numerical model of the power station of Bemposta II was developed using FLAC3D [55] and simulates the construction process and the complex geometry of the shaft. The mesh was developed with an automatic mesh generator [59] and it is composed by 59184 zones and 63075 grid-points [60] (Figure 14).

The rock mass surrounding the powerhouse cavern was simulated as an equivalent continuous medium. An elastic-perfectly plastic Mohr-Coulomb failure criterion with non-associated flow rule was assumed to represent the rock mass behavior. According to the geologic and geotechnical survey and the application of the GSI system, the following initial geomechanical parameters were set: $\phi^{\prime}=54^{\circ} ; c^{\prime}=2.65 \mathrm{MPa} ; E=15 \mathrm{GPa}$ and $v=0.2$.

The support system was composed by shotcrete and pre-casted concrete. The shotcrete was simulated using shell elements $0.20 \mathrm{~m}$ thick and the pre-casted concrete by volume elements. For both, a linear elastic and isotropic constitutive model with a Young modulus of $25 \mathrm{GPa}$ and a Poisson ratio of 0.2 was adopted. 
In the numerical model the construction sequence was simplified and a total of 6 excavation stages were considered. In the preliminary calculations it was verified that this simplification did not affect considerably the results because the rock mass behavior is almost elastic.

The field stress was set considering the results of the tests presented previously. In particular, the stress ratio in the direction $\mathrm{AA}^{\prime}$ (see Figure 12) was set to 2.0 and in the perpendicular direction to 1.0 .

Figure 15 presents the displacements magnitude in the rock mass surrounding the excavation. The computed values are low due to its overall good geomechanical quality. The maximum displacement is $3.7 \mathrm{~mm}$ in the horizontal direction of higher $\mathrm{K}_{0}$. The displacements around the excavation of the circular part are smaller than the ones near the rectangular part due to higher confinement loss and lower arch effect. This magnitude of displacements and the observation of the yielding zones which were almost absent, allowed concluding that the behavior of the rock mass is almost elastic.

\subsection{Results of back analysis}

In order to reduce the computational time of the study it was decided to take advantage of the symmetry of the shaft so the model was reduced to an half. This simplification did not significantly affect the computed values [60].

For the back analysis process it was decided to identify $E$ and $K_{0}$ which were the parameters with higher influence on the displacements. To carry out the back analysis with the ES algorithm interval ranges for the parameters to identify must be set. The adopted ranges were the following: $E[10 ; 60]$ and $K_{0}[1 ; 4]$ which obviously include the initial guess for the parameters used in the numerical model. 
Figure 16 represents the topology of the error function. It shows that a linear relation between both parameters exists that leads practically to the same error values. Therefore the problem is "ill-posed" due to the fact that the two measurements are carried out in the same direction and they are highly correlated and compromise the uniqueness of the solution. These results corroborate the conclusions obtained previously in the synthetic case. To obtain a better definition of the error function it would be necessary to increase the monitoring data.

In order to check the influence of the introduction of an additional extensometer in the back analysis process another synthetic study was carried out based on this real case. In this theoretical study an additional extensometer was considered, perpendicular to the existing one. The "real" displacements measured by the extensometers were calculated using the initial parameters $E=30 \mathrm{GPa}$ and $K_{0}=2.0$. These values are the optimal solution that the ES algorithm will search during the back analysis process. The ES algorithm was able to converge to the correct set of parameters showing high robustness in a few hundred calculations (Table 12).

Figure 17 shows the topology of the error function for this theoretical calculation. Comparing the topology of this error function with the previous one (Figure 16) it can be concluded that the introduction of one additional extensometer improved the configuration of the error function and the definition of the optimal solution. A more accurate definition of the range of possible $K_{0}$ values was achieved since in this case the valley of the error function is restricted to the interval $[1.7 ; 2.2]$. For $E$ this interval is much wider, between approximately $25 \mathrm{GPa}$ to $35 \mathrm{GPa}$, in which the error value is practically constant. However, and in spite the complexity of the error function, the ES algorithm was able to identify the global minimum in an acceptable number of calculations. 


\section{CONCLUSIONS}

The back analysis of geomechanical parameters can raise complex mathematical problems mainly concerned with the convergence process due to the high complexity of the error function. In fact, mainly when more complex constitutive models are considered, given the increased non-linearity of the problem, and when measurements are insufficient, the identification of the optimum set of parameters can be very difficult. Algorithms of the evolutionary computation field provide global optimization techniques that can avoid some of these problems. Normally, GA are used in optimization applications in geotechnics but the ES algorithms, another branch of evolutionary computation, have important features however is almost unknown in geotechnical applications.

In this work, different types of optimization algorithms were applied in a synthetic problem of a tunnel excavation, both in elasticity and elasto-plasticity, for the assessment of their performance. Special emphasis was given to the ES algorithm due to its novelty in geotechnics. Also classical gradient-based algorithms and a GA were applied under different circumstances of available monitoring data and parameters to identify in order to establish a comparison base with the ES algorithm.

The used gradient-based algorithms were the steepest descent, conjugate gradient and QuasiNewton. It was stated, as in previous studies, that these algorithms have a satisfactory performance when the error function is strictly convex and presents a single local minimum. For complex topologies of the error function, like the ones existing when yielding in the model occurs these algorithms behave poorly.

Both algorithms from the field of evolutionary computation showed to have similar and very satisfactory performance in terms of robustness and efficiency in most of the tested cases of the 
synthetic problem even for highly complex error functions. It was shown that the ES algorithm has interesting capabilities and it is a competitive alternative to the use of GA in geotechnical applications of back analysis.

For the case study of Bemposta II powerhouse a back analysis process was carried out for the identification of $E$ and $K_{0}$ using the ES algorithm. Due to the low number of parameters to identify and the consideration of an elastic model for the rock mass, this calculation could be carried out with a gradient-based algorithm. However, the intention was to analyse the performance of the ES algorithm.

The back analysis process was not able to identify the set of optimal geomechanical parameters due to the fact that the error function presents a constant value for a linear variation of the parameters. This was due to the limited available monitoring data. It was shown by a theoretical calculation that one additional extensometer would increase the definition of the error function topology and could allow the identification of the correct set of parameters. This conclusion shows that back analysis calculations can not only provide better knowledge about the involved formations during construction but can also provide some guidelines in the definition of monitoring plans.

\section{ACKNOWLEDGEMENTS}

The authors wish to acknowledge the EDP Company (Portuguese Electricity Company) for providing all the information needed for this study. 


\section{REFERENCES}

[1] Calvello M and Finno RJ (2004) Selecting parameters to optimize in model calibration by inverse analysis. Comput Geotech 2004; 31(5):411-25.

[2] Finno RJ, Calvello M (2005) Supported excavations: observational method and inverse modeling. J Geotech Geoenviron Eng 2005; 131(7): 826-36.

[3] Gioda G (1985) Some remarks on back analysis and characterization problems in geomechanics. In Fifth International Conference on Numerical Methods in Geomechanics, Nagoya, Japan, Kawamoto T, Ichikawa Y (eds). Balkema: Rotterdam, 1985; 47-61.

[4] Lecampion B, Constantinescu A, Nguyen Minh D (2002) Parameter identification for lined tunnels in viscoplastic medium. International Journal for Numerical and Analytical Methods in Geomechanics 2002; 26:1191-1211.

[5] Zentar R, Hicher P, Moulin G (2001) Identification of soil parameters by inverse analysis. Computers and Geotechnics 2001; 28:129-144.

[6] Miranda T (2007) Geomechanical parameters evaluation in underground structures. Artificial intelligence, Bayesian probabilities and inverse methods. PhD's thesis. University of Minho, Guimarães, Portugal, 291p.

[7] Levasseur S, Malécot Y, Boulon M, Flavigny E (2008) Soil parameter identification using a genetic algorithm. Int J Numer Anal Meth in Geomechanics, 2008; 32:189-213.

[8] Levasseur S, Malécot Y, Boulon M, Flavigny E (2009) Statistical inverse analysis based on genetic algorithm and principal component analysis: method and developments using synthetic data. International Journal for Numerical and Analytical Methods in Geomechanics 2009; $33: 1485-1511$.

[9] Levasseur S, Malécot Y, Boulon M, Flavigny E (2010) Statistical inverse analysis based on genetic algorithm and principal component analysis: applications to excavation problems and pressuremeter tests. International Journal for Numerical and Analytical Methods in Geomechanics 2010; 34:471-491. 
[10] Oreste, P (2005) Back-analysis techniques for the improvement of the understanding of rock in underground constructions. Tunnelling and Underground Space Technology, 20: 7-21. [11] Eclaircy-Caudron S, Dias D, Chantron L and Kastner R (2006) Evaluation of a back analysis method on simple tests. In Fourth Int. FLAC Sym. on Numerical Modelling in Geomech, 8p. Madrid, Spain.

[12] Rechea C, Levasseur S, Finno R (2008) Inverse analysis techniques for parameter identification in simulation of excavation support systems. Computers and Geotechnics 2008; 35(3):331-345.

[13] Papon A, Riou Y, Dano C, Hicher P-Y 2011 Single- and multi-objective genetic algorithm optimization for identifying soil parameters. Int. J. Numer. Anal. Meth. Geomech. DOI: 10.1002/nag.1019.

[14] Levasseur S, Malecot Y, Boulon M, Flavigny E (2007) Soil parameter identification using a genetic algorithm. Int. J. Numer. Anal. Meth. Geomech, 32:189-213.

[15] Gioda G (1980) Indirect identification of the average elastic characteristics of rock masses. "Int. Conf. on Structure and Foundation on Rock". Sydney, Australia, 8: 65-73.

[16] Gioda G and Maier G (1980) Direct search solution of an inverse problem in elastoplasticity: identification of cohesion, friction angle and in situ stress by pressure tunnel tests. Int. Journal for Numerical Methods in Engineering, 15: 1823-1848.

[17] Cividini A, Jurina L and Gioda G (1981) Some aspects of characterization problems in geomechanics. International Journal of Rock Mechanics and Mining Science, 18: 487-503.

[18] Sakurai S and Takeuchi K (1983) Back analysis of measured displacements of tunnels. Rock Mech and Rock Eng. 16: 173-180.

[19] Swoboda G, Ichikawa Y, Dong Q and Mostafa Z. (1999) Back analysis of large geotechnical models. International Journal for Numerical and Analytical Methods in Geomechanics, 23: 1455-1472.

[20] Deng D (2001) Back analysis problems in Geotechnics. A method based on the virtual work principle (in French). Ph.D. thesis, École Nationale de Ponts et Chaussées. 
[21] Jeon Y and Yang H. (2004) Development of a back analysis algorithm using FLAC. International Journal of Rock Mechanics and Mining Science, 41(1): 447-453.

[22] Ledesma A, Gens A, Alonso EE (1996) Estimation of parameters in geotechnical back analysis. 1 - Maximum likelihood approach. Comput Geotech 1996; 18(1):1-27.

[23] Gens A, Ledesma A, Alonso EE (1996) Estimation of parameters in geotechnical back analysis. 2 - Application to a tunnel excavation problem. Comput Geotech 1996; 18(1):29-46.

[24] Gioda G and Locatelli L (1999) Back analysis of the measurements performed during the excavation of a shallow tunnel in sand. Int J Numer Anal Meth Geomech 1999;23:1407-25.

[25] Lecampion B and Contantinescu A (2005) Sensitivity analysis for parameter identification in quasi-static poroelasticity. Int J Numer Anal Meth Geomech 2005; 29:163-85.

[26] Miranda T, Eclaircy-Caudron S, Dias D, Gomes Correia A, Costa L (2010) Back analysis of geomechanical parameters by optimization of a 3D model of an underground structure. Tunnelling and Underground Space Technology, 26 (2011), 659-673.

[27] Anandarajah A and Agarwal D (1991) Computer-aided calibration of soil plasticity model. Int J Numer Anal Meth Geomech 1991;15:835-56.

[28] Pal S, Wathugala G, Kundu S (1996) Calibration of a constitutive model using genetic algorithms. Computers and Geotechnics, 19(4): 325-347.

[29] Samarajiva P, Macari E, Wathugala W (2005) Genetic algorithms for the calibration of constitutive models for soils. International Journal of Geomechanics, 5(3): 206-217.

[30] Iding R, Pister K and Taylor R (1974) Identification of nonlinear elastic solids by a finite element method. Computer Methods in Applied Mechanics and Engineering, 4: 121-142.

[31] Imre E (1994) Model validation for the oedometric relaxation test. In Proc. of the 13th Int. Conf. on Soil Mech. and Foundation Eng., 1123-1126, New Delhi, India.

[32] Ou C and Tang Y (1994) Soil parameter determination for deep excavation analysis by optimization. J Chin Inst Eng 1994;17(5):671-88. 
[33] Hashash Y, Levasseur S, Osouli A, Finno R, Malecot Y (2010) Comparison of two inverse analysis techniques for learning deep excavation response. Computers and Geotechnics, 37 (2010), 323-333.

[34] Arai K, Ohta H, Kojima K (1986) Application of back analysis to several test embankments on soft clay deposits. Soil Found 1986; 26(2):60-72.

[35] Honjo Y, Wen-Tsung L, Guha S (1994) Inverse analysis of an embankment on soft clay by extended Bayesian method. Int J Numer Anal Meth Geomech 1994; 18:709-34.

[36] Wakita E and Matsuo M (1994) Observational design method for earth structures constructed on soft ground. Géotechnique 1994; 44(4): 747-55.

[37] Simpson A, Priest S (1993) The application of genetic algorithms to optimization problems in geotechnics. Computers and Geotechnics, 15: 1-19.

[38] Goh A (1999) Genetic algorithm search for critical slip surface in multiple-wedge stability analysis. Canadian Geotechnical Journal, 536: 383-391.

[39] Costa L, Oliveira P (2001) Evolutionary Algorithms Approach to the Solution of Mixed Integer Non-Linear Programming Problems. Computers \& Chemical Engineering 25, Issues 2-3, Elsevier, 257-266.

[40] Costa L (2006) A new parameter-less evolution strategy for solving unconstrained global optimization problems. Wseas Transactions On Mathematics, 5(11), 1247-1254.

[41] Dianati M, Song I, Treiber M (2002) An Introduction to genetic Algorithms and Evolution Strategies, Technical report, University of Waterloo, Ontario, Canada.

[42] Holland J (1975) Adaptation in natural and artificial systems. University of Michigan press: Ann Arbor, MI.

[43] Costa L (2003) Evolutionary algorithms in optimization uni and multi-objective (in Portuguese). PhD's thesis. University of Minho, Guimarães, Portugal, 237p

[44] Costa L, Fernandes L, Figueiredo I, Júdice J, Leal R, Oliveira P (2004) Multiple- and single-objective approaches to laminate optimization with genetic algorithms. Structural and Multidisciplinary Optimization, Springer-Verlag Heidelberg, Volume 27, Numbers 1-2, 55-65. 
[45] Hoffmeister F, and Bäck T (1991) Genetic Algorithms and evolution strategies: Similarities and differences. Lecture Notes in Computer Science, 1991, Volume 496/1991, 455469, DOI: 10.1007/BFb0029787

[46] Rechenberg I (1973) Evolutionsstrategie: Optimierung technischer Systeme nach Prinzipien der biologischen Evolution. Friedrich Frommann Verlag, Stuttgart, 1973.

[47] Schwefel H-P (1977) Numerisehe Optimierung yon Computer-Modellen mittels der Evolutionsstrategie. Interdisciplinary systems research; 26. Birkhauser, Basel, FRG, 1977.

[48] Schwefel H-P (1981) Numerical Optimization of Computer Models. Wiley, Chichester, 1981.

[49] Schwefel H-P (1981) Optimum seeking methods: Subroutines for the minimization of nonlinear functions of several variables by means of direct (derivative-free) methods. Interner Bericht KFA-STE-IB-7/81, Kernforschungsanlage Jfilich GmbH, Jfilich, FRG, October 1981.

[50] Schwefel H-P (1995) Evolution and Optimal Seeking. John Wiley and Sons, 1995.

[51] Bäck T, Hammel U, Schwefel H-P (1996) Evolutionary computation: an overview, Proceedings of the Third IEEE Conference on Evolutionary Computation, IEEE Press, pp. 2029, 1996.

[52] Rechenberg I 1994. Evolutionsstrategie'94. Stuttgard: Frommann-Holzboog.

[53] Cardoso M (2011) Inverse analysis of geomechanical parameters in underground works: comparing different techniques of optimization (in Portuguese). MsC thesis, University of Minho, Guimarães, Portugal, 115p.

[54] Matlab (2009) The Language of Technical Computing Version 7.9. User Manual.

[55] Itasca (2005) FLAC - Fast lagrangian analysis of continua. Version 5.0 User's manual, Minneapolis, USA.

[56] Lima C, Resende E, Esteves C, Neves J (2011) Bemposta II Powerhouse Shaft. Geotechnical Characterization, Design and Construction. $12^{\text {th }}$ International Congress on Rock Mechanics. October 19-22, Beijing, 6p (to be published). 
[57] EDP (2007) Power reinforcement of Bemposta hydroelectric scheme. A1- Studies of geologic and geotechnical characterization (in Portuguese), 90p.

[58] Lamas L (2010) Characterization of rock mass and achievement of parameters of design. Lecture in scope of Tunnels and Underground structures at University of Minho, 11 pp. 66-77. [59] Simulation Works (2010) Designs software that automate the most human intensive and costly aspects of Mechanical Computer-Aided Engineering (MCAE). http://www.siw.com/. Accessed 22 May 2010.

[60] Moreira N (2010) Numerical modelling and inverse analysis of geomechanical parameters of the power station of Bemposta II (in Portuguese). MsC thesis, University of Minho, Guimarães, Portugal, 73p. 


\section{Figure Caption}

Figure 1 - Evolution stages of the $(\mu+\lambda)$ - ES algorithm (adapted from Costa, 2003).

Figure 2 - Numerical model used in the parametric study of back analysis.

Figure 3 - Type and direction of measurements considered in the parametric study of back analysis.

Figure 4 - Topology of the error function for the elastic case with two vertical measurements.

Figure 5 - Topology of the error function on the identification of $\mathrm{E}$ and $\mathrm{K}_{0}$ for the case of using three measurements. a) 3D view b) Plan view.

Figure 6 - Results obtained with the three gradient back analysis algorithms.

Figure 7 - Topology of the error function for case 1: a) 3D view b) 2D view.

Figure 8 - Error function topologies for case 5 for the following geomechanical parameters: a, b)

$c^{\prime}$ and $\phi^{\prime}$; c,d) $E$ and $\phi^{\prime}$; e, f) $E$ and $c^{\prime}$.

Figure 9 - Topology of error function for case 8 a) 3D view b) 2D view.

Figure 10 - Topology of error function for case 10: a) 3D view b) 2D view.

Figure 11 - Powerhouse shaft: current section plan view (left) and hydraulic circuit and turbine axis vertical section (right).

Figure 12 - Scheme of the extensometer position.

Figure 13 - Measurements of the double extensometer.

Figure 14 - 3D mesh developed for the Bemposta II powerhouse.

Figure 15 - Displacement magnitude for the last excavation phase: a) Longitudinal section in direction $\mathrm{AA}^{\prime} \mathrm{b}$ ) Horizontal section at $14 \mathrm{~m}$ of the shaft base.

Figure 16 - Topology of error function a) 3D view b) 2D view.

Figure 17 - Topology of the error function for the theoretical calculation: a) 3D view b) 2D view 
Table 1 - Main parameters of the used ES algorithm.

\begin{tabular}{lc}
\hline \multicolumn{1}{c}{ Definition of the parameter } & Value \\
\hline Maximum number of calculations & 300 \\
Size of parents population $(\mu)$ & 5 \\
Number of recombinations & 5 \\
Size of offspring population $(\lambda)$ & 50 \\
Selection type (“+” or “,”) & + \\
Type of recombination & Discrete \\
Self-adaptation method & Anisotropic \\
\hline
\end{tabular}


Table 2 - Results of the identification process of $E$ and $K_{0}$ with two displacement measurements.

\begin{tabular}{ccccc}
\hline \multirow{2}{*}{ Case } & Deviations & \multirow{2}{*}{$\begin{array}{c}\text { Number of } \\
\text { calculations }\end{array}$} & \multicolumn{2}{c}{ Identified values } \\
\cline { 5 - 5 } & & 7 & 2.280 & 0.566 \\
GB_1 & $25 \%(+)$ & 7 & 2.683 & 0.233 \\
GB_2 & $50 \%(+)$ & 4 & 2.085 & 0.706 \\
GB_3 & $10 \%(+)$ & 4 & 2.797 & 0.084 \\
GB_4 & $50 \%(+)$ for $E$ and $50 \%(-)$ for $K_{0}$ & & \\
\hline
\end{tabular}


Table 3 - Results of the identification process of $E$ and $K_{0}$ with one horizontal and one vertical displacement measurement.

\begin{tabular}{ccccc}
\hline \multirow{2}{*}{ Case } & Deviations & \multirow{2}{*}{$\begin{array}{c}\text { Number of } \\
\text { calculations }\end{array}$} & \multicolumn{2}{c}{ Identified values } \\
\cline { 5 - 5 } & & 16 & 2.012 & 0.802 \\
GB_5 & $25 \%(+)$ & 10 & 2.066 & 0.811 \\
GB_6 & $50 \%(+)$ & 10 & 2.083 & 0.810 \\
GB_7 & $10 \%(+)$ & n.c. & - & - \\
GB_8 & $50 \%(+)$ for $E$ and $50 \%(-)$ for $K_{0}$ & &
\end{tabular}

n.c. - no convergence was attained. 
Table 4 - Results of the identification process of $E$ and $K_{0}$ with three and four displacements

\begin{tabular}{|c|c|c|c|c|c|}
\hline \multirow{2}{*}{ Case } & \multirow{2}{*}{ Deviations } & \multirow{2}{*}{$\begin{array}{l}\text { Number of } \\
\text { calculations }\end{array}$} & \multirow{2}{*}{ Measurements } & \multicolumn{2}{|c|}{ Identified values } \\
\hline & & & & $E(\mathrm{GPa})$ & $K_{0}$ \\
\hline GB_9 & $25 \%(+)$ & 16 & 3 & 2.058 & 0.807 \\
\hline GB_10 & $50 \%(+)$ & 25 & 3 & 2.025 & 0.803 \\
\hline GB_11 & $10 \%(+)$ & 13 & 3 & 2.038 & 0.820 \\
\hline GB_12 & $\begin{array}{c}50 \%(+) \text { for } E \text { and } 50 \% \text { (-) for } \\
K_{0}\end{array}$ & 37 & 3 & 2.061 & 0.799 \\
\hline GB_13 & $\begin{array}{c}25 \%(+) \text { for } K_{0} \text { and } 25 \%(-) \text { for } \\
E\end{array}$ & 7 & 3 & 1.970 & 0.794 \\
\hline GB_14 & $50 \%(-)$ & 16 & 3 & 1.940 & 0.796 \\
\hline GB_15 & $25 \%(+)$ & 16 & 4 & 1.986 & 0.799 \\
\hline GB_16 & $\begin{array}{c}50 \%(+) \text { for } E \text { and } 50 \%(-) \text { for } \\
K_{0}\end{array}$ & 25 & 4 & 2.032 & 0.788 \\
\hline
\end{tabular}


Table 5 - Results of the identification processes for $c^{\prime}$ and $\phi^{\prime}$

\begin{tabular}{|c|c|c|c|c|c|c|}
\hline \multirow[t]{2}{*}{ Case } & \multirow[t]{2}{*}{ Algorithm } & \multirow[t]{2}{*}{ Deviations } & \multirow{2}{*}{$\begin{array}{l}\text { Number of } \\
\text { calculations }\end{array}$} & \multirow[t]{2}{*}{ Measurements* } & \multicolumn{2}{|c|}{ Identified values } \\
\hline & & & & & $c^{\prime}(\mathrm{kPa})$ & $\phi^{\prime}\left({ }^{\circ}\right)$ \\
\hline GB_25 & \multirow{6}{*}{$\mathrm{SD}$} & $10 \%(+)$ & 10 & 3 & 54.78 & 31.20 \\
\hline GB_26 & & $25 \%(+)$ & 19 & 2 & 59.14 & 30.35 \\
\hline GB_27 & & $25 \%(-)$ & 7 & 2 & 39.62 & 33.65 \\
\hline GB_28 & & $25 \%(+)$ & 16 & 3 & 60.20 & 30.33 \\
\hline GB_29 & & $25 \%(+)$ & 10 & 4 & 60.17 & 30.14 \\
\hline GB_30 & & $25 \%(+)$ for $c^{\prime}$ and $25 \%(-)$ for $\phi^{\prime}$ & 7 & 3 & 63.67 & 29.84 \\
\hline GB_31 & \multirow{3}{*}{ QN } & $25 \%(+)$ & n.c. & 3 & - & - \\
\hline GB_32 & & $25 \%(-)$ & n.c. & 3 & - & - \\
\hline GB_33 & & $25 \%(+)$ for $c^{\prime}$ and $25 \%(-)$ for $\phi^{\prime}$ & n.c. & 3 & - & - \\
\hline GB_34 & \multirow{3}{*}{ CG } & $25 \%(+)$ & 16 & 3 & 58.67 & 30.35 \\
\hline GB_35 & & $25 \%(-)$ & n.c. & 3 & - & - \\
\hline GB_36 & & $25 \%(+)$ for $c^{\prime}$ and $25 \%(-)$ for $\phi^{\prime}$ & n.c. & 3 & - & - \\
\hline
\end{tabular}

$* 2$ measurements: vertical displacement in the crown and horizontal stress in the wall; 3 measurements: equal to the previous plus the horizontal displacement in the wall; 4 measurements: equal to the previous plus vertical stress in the crown 
Table 6 - Cases of the parametric study of back analysis using the GA and ES algorithms

\begin{tabular}{ccccc}
\hline \multirow{2}{*}{ Model } & Case & $\begin{array}{c}\text { Geomechanical } \\
\text { Parameters }\end{array}$ & \multicolumn{2}{c}{ Monitored displacements } \\
\cline { 3 - 5 } Elastic & Number & Location \\
& EA_1 & $E, K_{0}$ & 4 & arch, wall, surface and floor \\
& EA_2 & $E, K_{0}$ & 2 & wall and arch \\
& EA_3 & $E, K_{0}$ & 2 & wall and surface \\
& EA_4 & $E, K_{0}$ & 2 & surface and arch \\
\hline \multirow{5}{*}{ Plastic } & $E, c^{\prime}, \phi^{\prime}$ & 4 & arch, wall, surface and floor \\
& EA_5 & $E, c^{\prime}$ & 4 & arch, wall, surface and floor \\
& EA_6 & $E, \phi^{\prime}$ & 4 & arch, wall, surface and floor \\
& EA_7 & $c^{\prime}, \phi^{\prime}$ & 4 & arch, wall, surface and floor \\
& EA_9 & $E, c^{\prime}, \phi^{\prime}$ & 2 & arch and wall \\
& EA_10 & $c^{\prime}, \phi^{\prime}$ & 2 & arch and wall \\
& EA_11 & $E, c^{\prime}, \phi^{\prime}$ & 2 & surface and wall \\
\hline
\end{tabular}


Table 7 - Results for case EA_1

\begin{tabular}{|c|c|c|c|}
\hline \multirow{2}{*}{ Algorithm } & \multirow{2}{*}{ Intervals } & \multicolumn{2}{|c|}{ Parameters } \\
\hline & & $E(\mathrm{GPa})$ & $K_{0}$ \\
\hline \multirow{3}{*}{ GA } & $\begin{array}{c}E=[1.5 ; 3] \times 10^{9} \\
K_{0}=[0.6 ; 1]\end{array}$ & 1.999 & 0.800 \\
\hline & $\begin{array}{l}E=[1 ; 4] \times 10^{9} \\
K_{0}=[0.6 ; 1.5]\end{array}$ & 1.999 & 0.800 \\
\hline & $\begin{array}{c}E=[0.5 ; 10] \times 10^{9} \\
K_{0}=[0.3 ; 2]\end{array}$ & 2.043 & 0.779 \\
\hline \multirow{3}{*}{ ES } & $\begin{array}{c}E=[1.5 ; 3] \times 10^{9} \\
K_{0}=[0.6 ; 1]\end{array}$ & 1.999 & 0.803 \\
\hline & $\begin{array}{l}E=[1 ; 4] \times 10^{9} \\
K_{0}=[0.6 ; 1.5]\end{array}$ & 1.999 & 0.817 \\
\hline & $\begin{array}{c}E=[0.5 ; 10] \times 10^{9} \\
K_{0}=[0.3 ; 2]\end{array}$ & 2.035 & 0.803 \\
\hline
\end{tabular}


Table 8 - Results for cases EA_2, EA_3 and EA_4

\begin{tabular}{|c|c|c|c|c|c|c|c|}
\hline \multirow{3}{*}{ Algorithm } & \multirow{3}{*}{ Intervals } & \multicolumn{6}{|c|}{ Case } \\
\hline & & \multicolumn{2}{|c|}{2} & \multicolumn{2}{|c|}{3} & \multicolumn{2}{|c|}{4} \\
\hline & & $\begin{array}{c}E \\
(\mathrm{GPa})\end{array}$ & $K_{0}$ & $\begin{array}{c}E \\
(\mathrm{GPa})\end{array}$ & $K_{0}$ & $\begin{array}{c}E \\
(\mathrm{GPa})\end{array}$ & $K_{0}$ \\
\hline \multirow{3}{*}{ GA } & $\begin{array}{c}E=[1.5 ; 3] \times 10^{9} \\
K_{0}=[0.6 ; 1]\end{array}$ & 2.002 & 0.800 & 2.001 & 0.798 & 1.994 & 0.804 \\
\hline & $\begin{array}{l}E=[1 ; 4] \times 10^{9} \\
K_{0}=[0.6 ; 1.5]\end{array}$ & 2.031 & 0.801 & 2.005 & 0.790 & 1.883 & 0.893 \\
\hline & $\begin{array}{c}E=[0.5 ; 10] \times 10^{9} \\
K_{0}=[0.3 ; 2]\end{array}$ & 2.038 & 0.811 & 2.017 & 0.805 & 1.901 & 0.871 \\
\hline \multirow{3}{*}{ ES } & $\begin{array}{c}E=[1.5 ; 3] \times 10^{9} \\
K_{0}=[0.6 ; 1]\end{array}$ & 1.998 & 0.801 & 1.999 & 0.800 & 2.012 & 0.791 \\
\hline & $\begin{array}{l}E=[1 ; 4] \times 10^{9} \\
K_{0}=[0.6 ; 1.5]\end{array}$ & 1.999 & 0.817 & 1.992 & 0.804 & 1.999 & 0.817 \\
\hline & $\begin{array}{c}E=[0.5 ; 10] \times 10^{9} \\
K_{0}=[0.3 ; 2]\end{array}$ & 2.038 & 0.794 & 1.971 & 0.794 & 2.196 & 0.658 \\
\hline
\end{tabular}


Table 9 - Results for cases EA_5, EA_9 and EA_11

\begin{tabular}{|c|c|c|c|c|}
\hline \multirow{2}{*}{ Algorithm } & \multirow{2}{*}{ Intervals } & \multicolumn{3}{|c|}{ Parameters } \\
\hline & & $E(\mathrm{GPa})$ & $\phi$ & $c^{\prime}(\mathrm{kPa})$ \\
\hline \multicolumn{5}{|c|}{ Case 5} \\
\hline \multirow{3}{*}{ GA } & $E=[1.5 ; 3] \times 10^{9}$ & & & \\
\hline & $\phi^{\prime}=\left[25^{\circ} ; 40^{\circ}\right]$ & 2.028 & 30.10 & 47.71 \\
\hline & $c^{\prime}=[35 ; 60] \times 10^{3}$ & & & \\
\hline \multirow{3}{*}{ ES } & $E=[1.5 ; 3] \times 10^{9}$ & & & \\
\hline & $\phi^{\prime}=\left[25^{\circ} ; 40^{\circ}\right]$ & 2.103 & 31.74 & 35.00 \\
\hline & $c^{\prime}=[35 ; 60] \times 10^{3}$ & & & \\
\hline \multicolumn{5}{|c|}{ Case 9} \\
\hline \multirow{3}{*}{ GA } & $E=[1.5 ; 3] \times 10^{9}$ & & & \\
\hline & $\phi^{\prime}=\left[25^{\circ} ; 40^{\circ}\right]$ & 1.988 & 30.28 & 48.76 \\
\hline & $c^{\prime}=[35 ; 60] \times 10^{3}$ & & & \\
\hline \multirow{3}{*}{ ES } & $E=[1.5 ; 3] \times 10^{9}$ & & & \\
\hline & $\phi^{\prime}=\left[25^{\circ} ; 40^{\circ}\right]$ & 2.117 & 30.44 & 41.93 \\
\hline & $c^{\prime}=[35 ; 60] \times 10^{3}$ & & & \\
\hline \multicolumn{5}{|c|}{ Case 11} \\
\hline \multirow{3}{*}{ GA } & $E=[1.5 ; 3] \times 10^{9}$ & & & \\
\hline & $\phi^{\prime}=\left[25^{\circ} ; 40^{\circ}\right]$ & 2.073 & 29.33 & 50.32 \\
\hline & $c^{\prime}=[35 ; 60] \times 10^{3}$ & & & \\
\hline \multirow{3}{*}{ ES } & $E=[1.5 ; 3] \times 10^{9}$ & & & \\
\hline & $\phi^{\prime}=\left[25^{\circ} ; 40^{\circ}\right]$ & 2.134 & 31.32 & 35.00 \\
\hline & $c^{\prime}=[35 ; 60] \times 10^{3}$ & & & \\
\hline
\end{tabular}


Table 10 - Results for cases EA_6, EA_7, EA_8 and EA_10

\begin{tabular}{|c|c|c|c|}
\hline Algorithms & Intervals & \multicolumn{2}{|c|}{ Parameters } \\
\hline \multicolumn{4}{|c|}{ Case 6 - Parameters $E(\mathrm{GPa})$ and $c^{\prime}(\mathrm{kPa})$} \\
\hline \multirow{2}{*}{ GA } & $E=[1.5 ; 3]$ & \multirow{2}{*}{1.999} & \multirow{2}{*}{49.99} \\
\hline & $c^{\prime}=[35 ; 60]$ & & \\
\hline \multirow{2}{*}{ ES } & $E=[1.5 ; 3]$ & \multirow{2}{*}{2.028} & \multirow{2}{*}{48.18} \\
\hline & $c^{\prime}=[35 ; 60]$ & & \\
\hline \multicolumn{4}{|c|}{ Case 7 - Parameters E (GPa) and $\phi^{\prime}\left({ }^{\circ}\right)$} \\
\hline \multirow{2}{*}{ GA } & $E=[1.5 ; 3]$ & \multirow{2}{*}{2.059} & \multirow{2}{*}{29.40} \\
\hline & $\phi^{\prime}=\left[25^{\circ} ; 40^{\circ}\right]$ & & \\
\hline \multirow{2}{*}{ ES } & $E=[1.5 ; 3]$ & \multirow{2}{*}{2.013} & \multirow{2}{*}{29.91} \\
\hline & $\phi^{\prime}=\left[25^{\circ} ; 40^{\circ}\right]$ & & \\
\hline \multicolumn{4}{|c|}{ Case 8 - Parameters c' $(\mathrm{kPa})$ and $\phi^{\prime}\left({ }^{\circ}\right)$} \\
\hline \multirow{2}{*}{ GA } & $c^{\prime}=[35 ; 60]$ & \multirow{2}{*}{46.91} & \multirow{2}{*}{30.48} \\
\hline & $\phi^{\prime}=\left[25^{\circ} ; 40^{\circ}\right]$ & & \\
\hline \multirow{2}{*}{ ES } & $c^{\prime}=[35 ; 60]$ & \multirow{2}{*}{47.46} & \multirow{2}{*}{30.33} \\
\hline & $\phi^{\prime}=\left[25^{\circ} ; 40^{\circ}\right]$ & & \\
\hline \multicolumn{4}{|c|}{ Case 10 - parameters $\phi^{\prime}\left({ }^{\circ}\right)$ and $\mathrm{c}^{\prime}(\mathrm{kPa})$} \\
\hline \multirow{2}{*}{ GA } & $c^{\prime}=[35 ; 60]$ & \multirow[t]{2}{*}{30.472} & \multirow{2}{*}{47.09} \\
\hline & $\phi^{\prime}=\left[25^{\circ} ; 40^{\circ}\right]$ & & \\
\hline \multirow{2}{*}{ ES } & $c^{\prime}=[35 ; 60]$ & \multirow[t]{2}{*}{31.06} & \multirow[t]{2}{*}{43.56} \\
\hline & $\phi^{\prime}=\left[25^{\circ} ; 40^{\circ}\right]$ & & \\
\hline
\end{tabular}


Table 11 - Geological and geotechnical zoning of the rock mass of Bemposta II hydroelectric scheme [28]

\begin{tabular}{|c|c|c|c|c|c|c|c|}
\hline Geotechnical & & & & RQD & & & $E_{\mathrm{m}}$ \\
\hline Zone & Lithology & Weathering & Fracturing & $(\%)$ & RMR & GSI & (GPa) \\
\hline \multirow[t]{2}{*}{ ZG4 } & Gnaissic granite & W4 a W5 & F4 a F5 & $<25$ & $<35$ & $<30$ & $<1$ \\
\hline & Migmatite & & & & & & \\
\hline \multirow[t]{2}{*}{ ZG3 } & Gnaissic granite & W3 a W3-4 & F4 a F5 & $<50$ & $30-56$ & $25-51$ & $1-6$ \\
\hline & Migmatite & & & & $32-57$ & $27-52$ & $1-7$ \\
\hline \multirow[t]{2}{*}{ ZG2 } & Gnaissic granite & W2-3 a W3 & F3 a F4 & $50-90$ & $50-69$ & $45-64$ & $5-17$ \\
\hline & Migmatite & & & & $48-70$ & $48-70$ & $5-22$ \\
\hline \multirow[t]{2}{*}{ ZG1 } & Gnaissic granite & W1 a W2 & F1 a F3 & $90-100$ & $>50$ & $>50$ & $>11$ \\
\hline & Migmatite & & & & $>60$ & $>60$ & $>15$ \\
\hline
\end{tabular}


Table 12 - Results of the theoretical study of back analysis using Bemposta II model.

\begin{tabular}{ccccc}
\hline \multirow{2}{*}{ Algorithm } & Intervals & \multicolumn{2}{c}{ Parameters } & \multirow{2}{*}{$\begin{array}{c}\text { Number of } \\
\text { calculations }\end{array}$} \\
\cline { 3 - 3 } Evolution Strategy & $\begin{array}{c}E=[10 ; 60] \times 10^{9} \\
K_{0}=[1 ; 4]\end{array}$ & 29.32 & 2.01 & 220 \\
\hline
\end{tabular}

